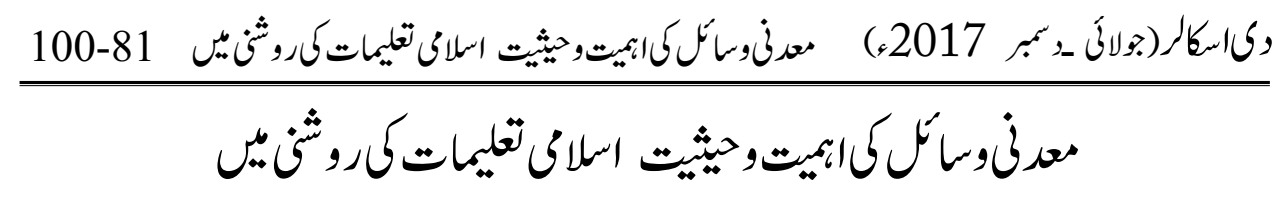

\title{
URDU -IMPORTANCE AND SIGNIFICANCE OF THE NATURAL RESOURCES IN THE LIGHT OF ISLAMIC INJUNCTIONS
}

\author{
Muhammad Umar ${ }^{*}$, Prof. Dr. Abdul Ali Achakzai ${ }^{* *}$ \\ The Scholar Islamic Academic Research Journal || Web: www.siarj.com || \\ P. ISSN: 2413-7480 || Vol. 3, No. 2 || June-December 2017 || P. 81-100 \\ DOI: $10.29370 /$ siarj/issue5ar5 \\ URL: https://doi.org/10.29370/siarj/issue5ar5 \\ License: Copyright c 2017 NC-SA 4.0
}

\begin{abstract}
:
The natural wealth that Allah endowed to earth at the time of its creation is called minerals and natural resources. Man is aware of the significance and importance of minerals since the ancient times and since then he has been benefitting from the minerals. But during the last two centuries, the way man has been benefitting from minerals, perhaps the ancient man had never thought of that. In future, the progress and prosperity of mankind will largely depend on the natural resources, and economy will depend on minerals; therefore, it becomes imperative that minerals and the land rich with minerals should be under vigilant protection. These should be spared from the clutches of the international powers in every possible way. The injunctions given by the Shâaria regarding minerals should be followed and implemented in every humanly possible way. The lands rich with minerals should be in the control of a government instead of individuals so that people may benefit from the blessings of Allah collectively, and as a nation instead of seeking help and assistance from other developed nations, we should inculcate in ourselves the capacity to extract them, refine them, and get maximum benefit ourselves from them

\footnotetext{
* Lecturer, Islamabad Model Postgraduate College, H-8, Islamabad, Email: muhammadumarumar80@gmail.com

** Dean Faculty of Education and Humanities, University of Baluchistan, Quetta Email: abdulali.uob@gmail.com
} 


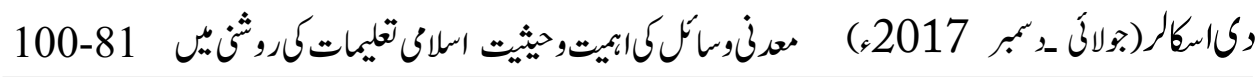
so that we could avoid dependence of others. The wealth got from the minerals should be used for welfare of the masses. Moreover, dishonesty and misappropriation of every sort should be avoided. Collective benefit should be supreme to the individual benefit.

KEYWORDS: Minerals, Injunctions, Protection /Preservation, Benefit, Rights

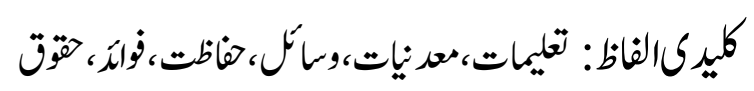

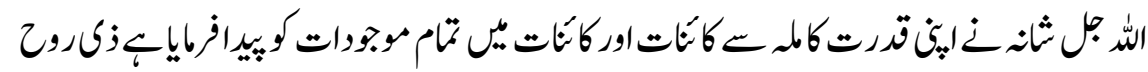

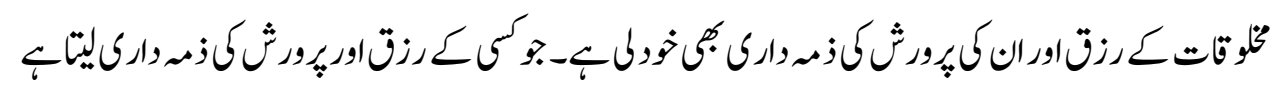

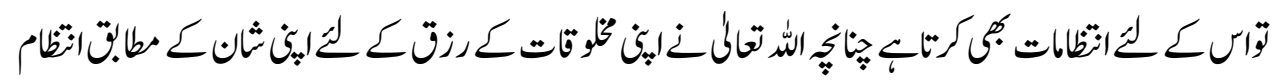

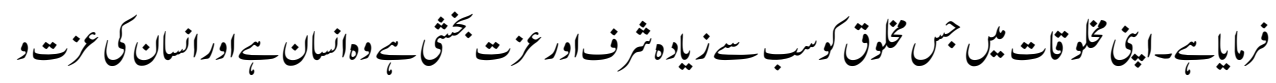

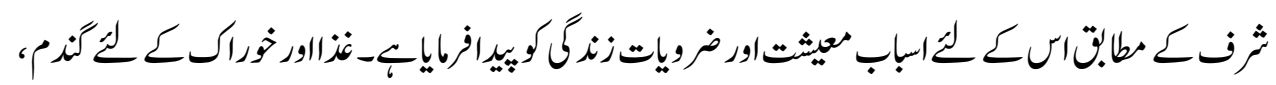

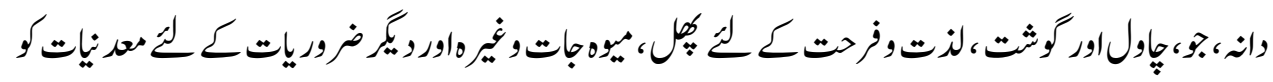

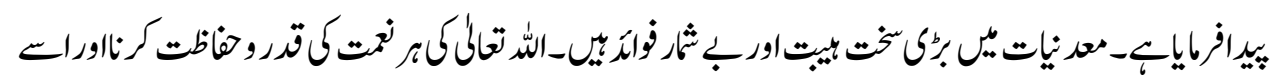

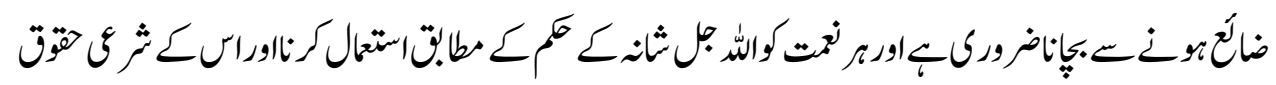

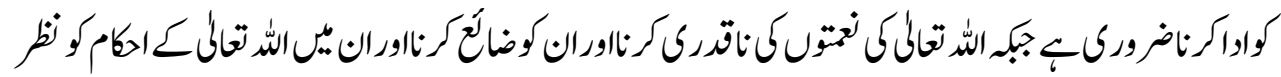

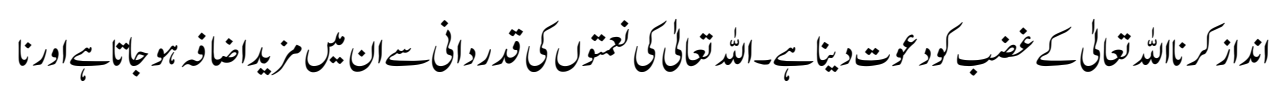

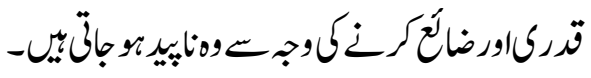
2

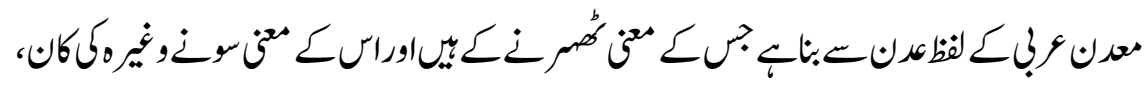

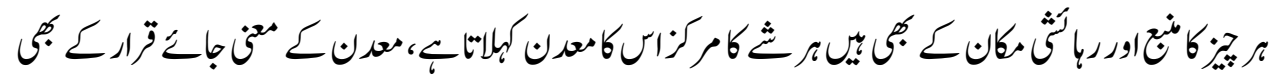

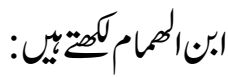
المعدن من العدن و هو الاقامةو منه يقال عدن بالمكان اذاقام بهو منه جنت عدن و مركز كل شى 


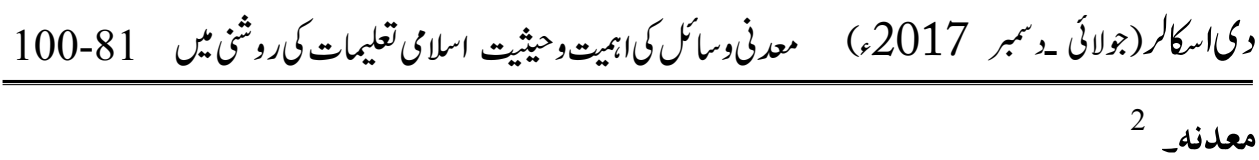

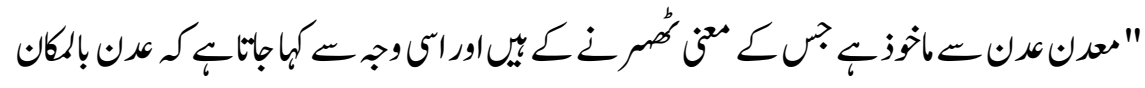

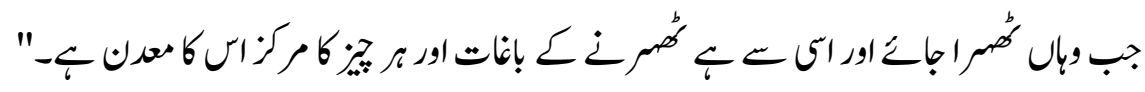

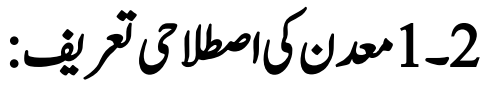

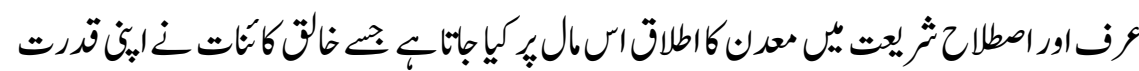

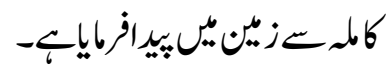

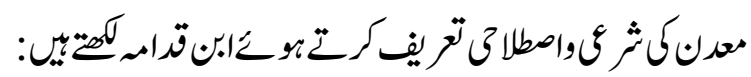

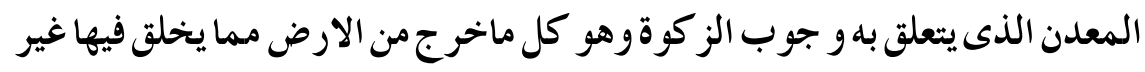

هاممالةقيمة. 3

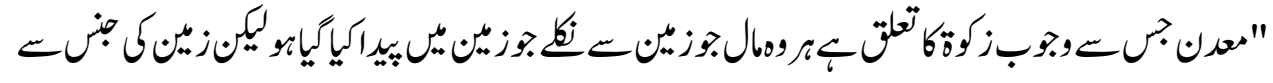

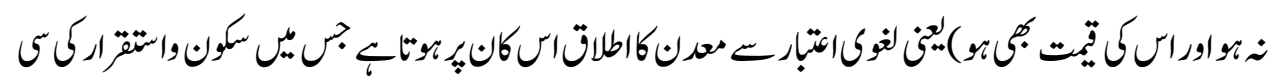

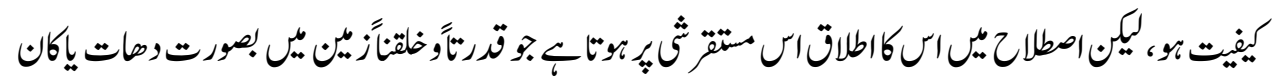

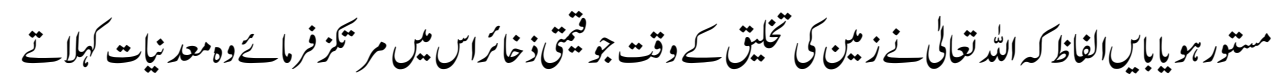

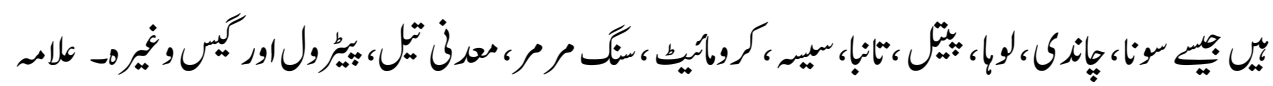

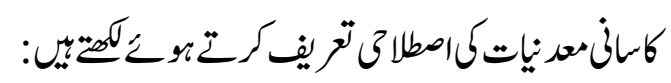

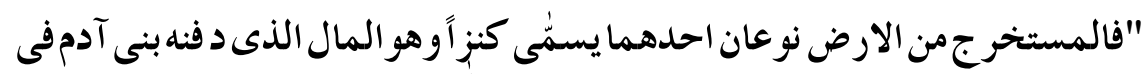

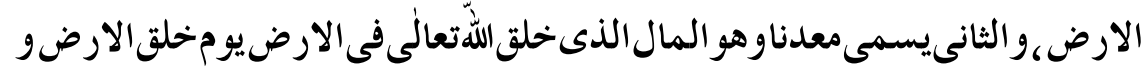

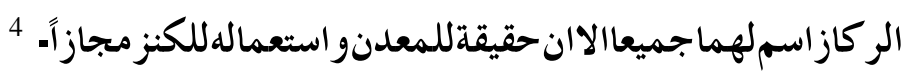

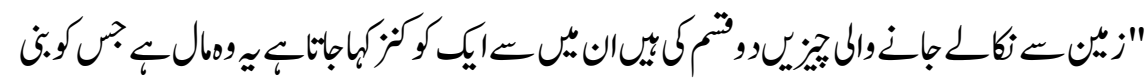

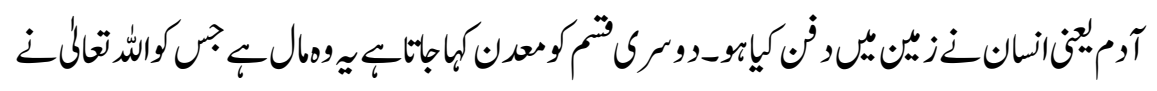

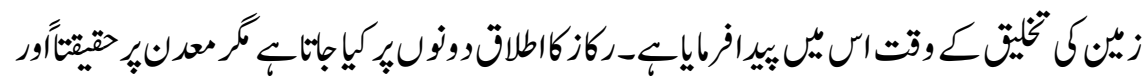

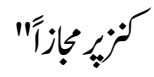

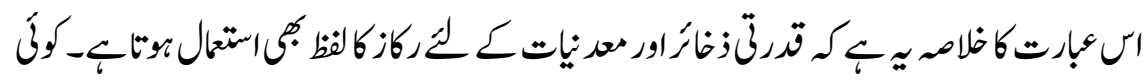

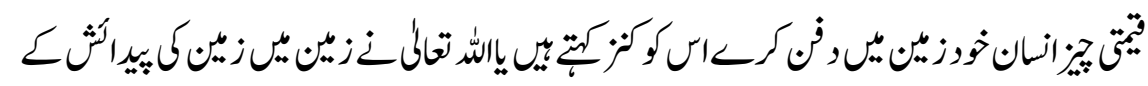




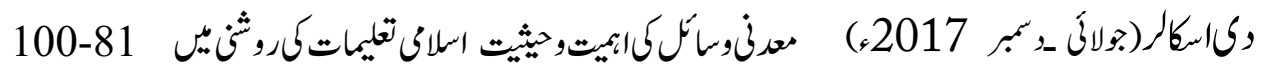

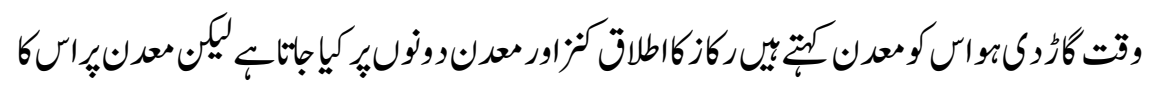

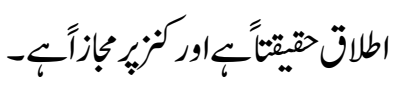

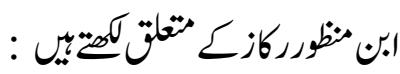

"والر كاز قطعذهبو فضةتخر جمن الارضو المعدنوفى الحمديث وفى الر كاز الخمس."

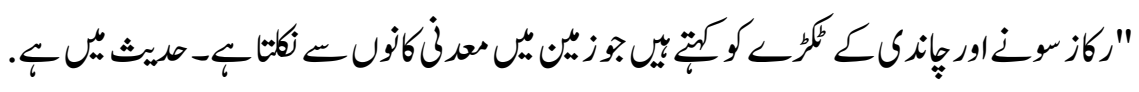

$$
\begin{aligned}
& \text { ركزئ نَسب- } \\
& \text { 3-مدمنإتك قتمي: }
\end{aligned}
$$

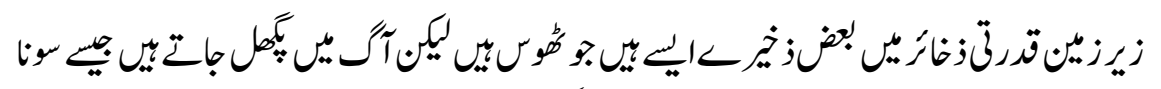

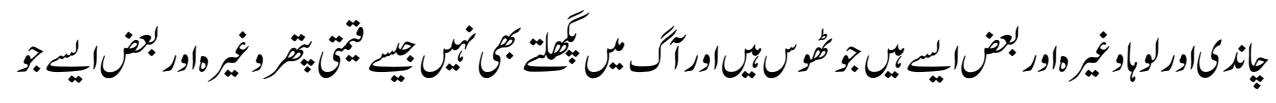

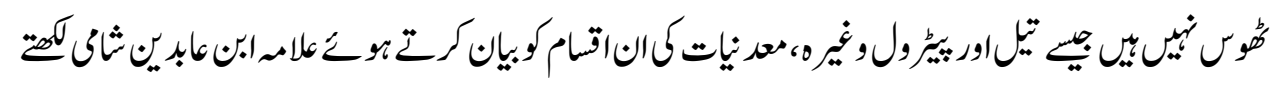

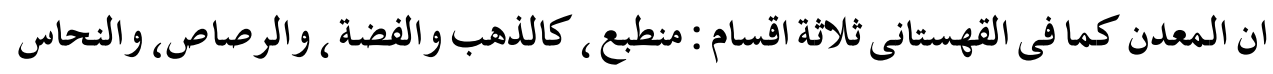

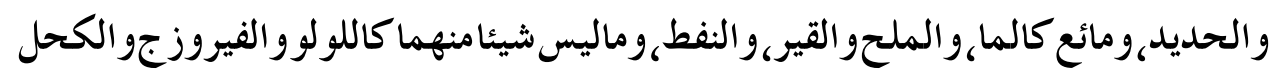

$$
\text { وغيرها. }
$$

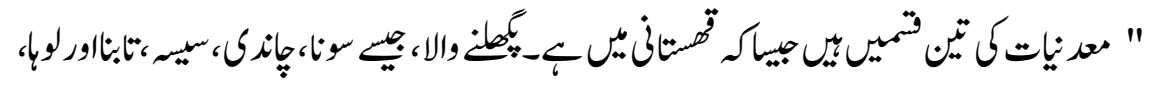

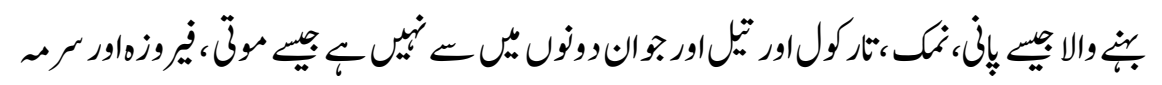

$$
\text { "نير- }
$$

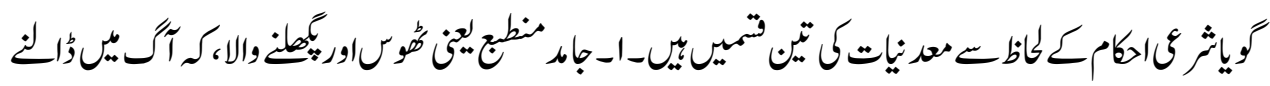

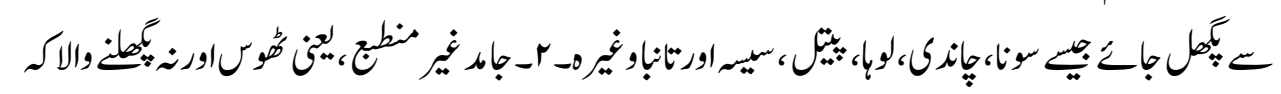

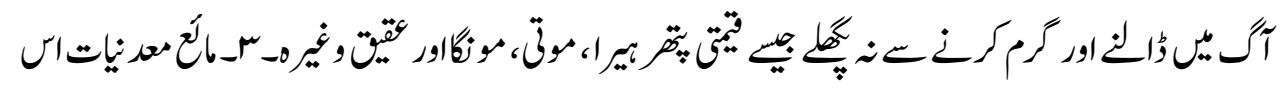

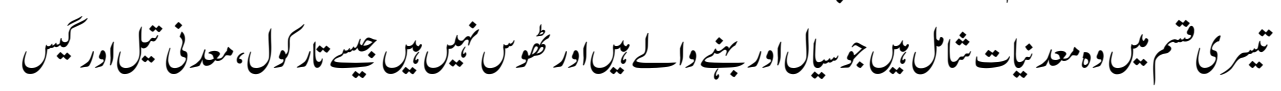

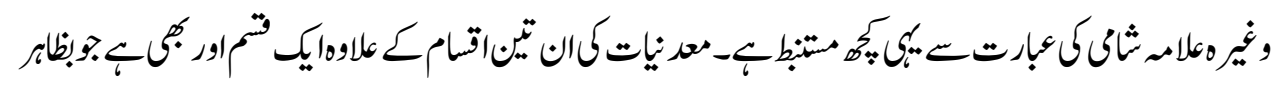

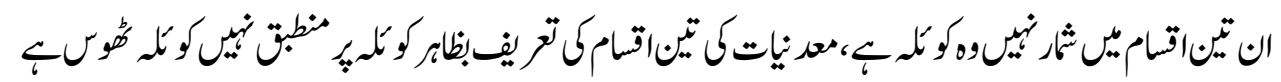

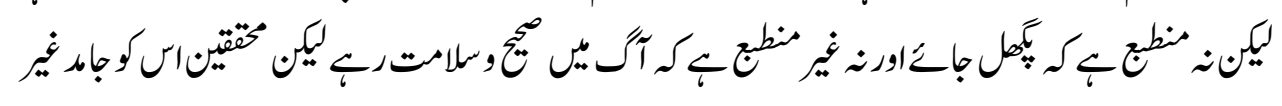




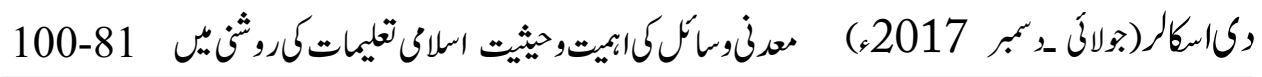

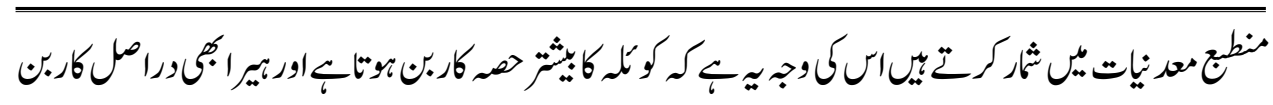

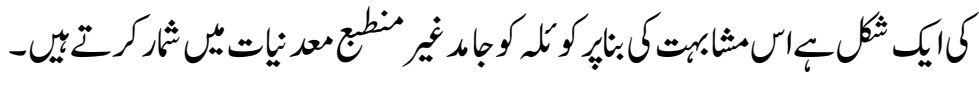

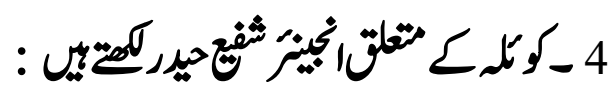

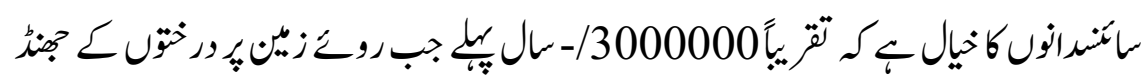

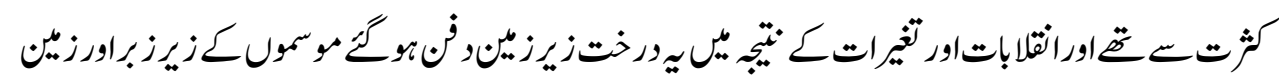

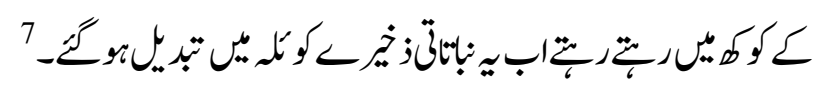

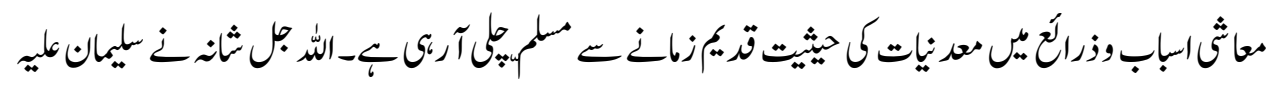

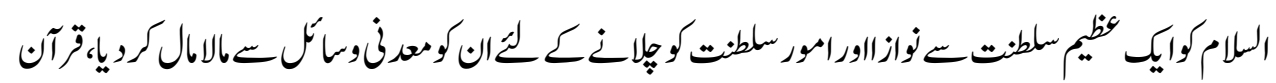

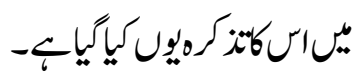

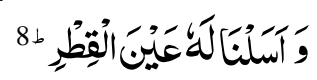

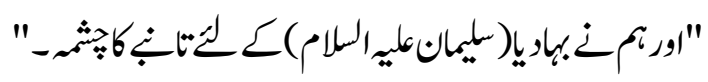

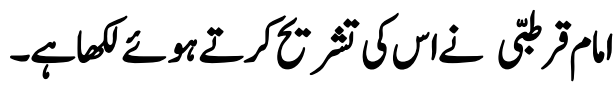
"قوله:و اسلنالهعين القطر، القطر النحاس، عن ابن عباس وغير اسيلت لهمسيرةثلاثةايام كمايسيل الماو

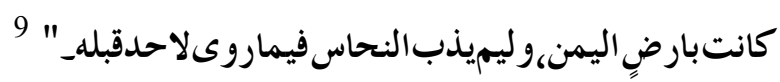

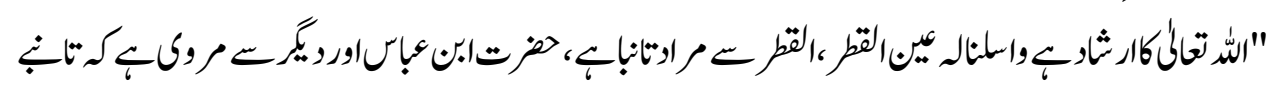

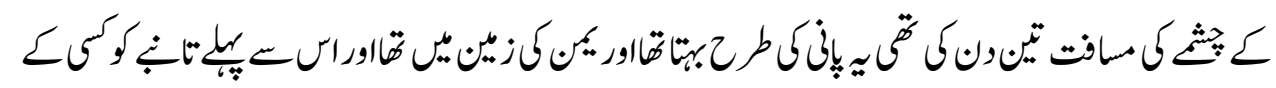

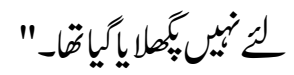

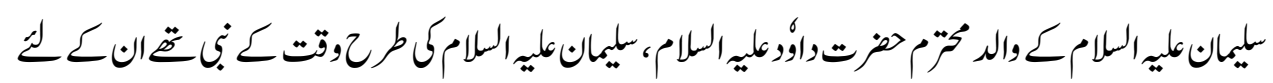

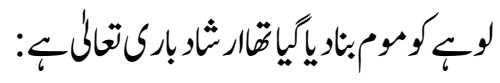

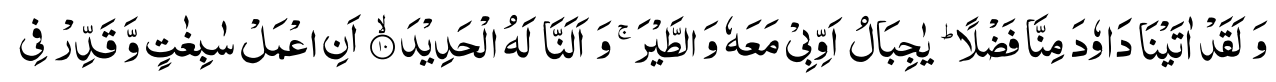

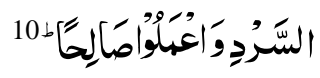

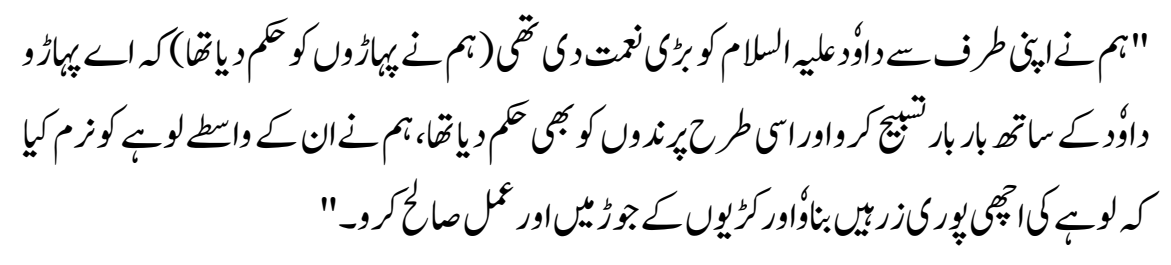




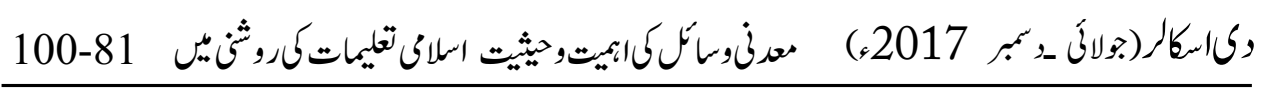

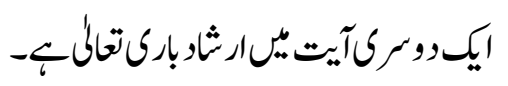

11

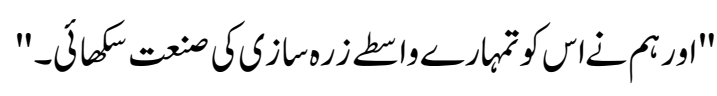

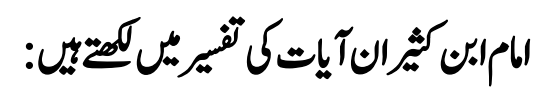

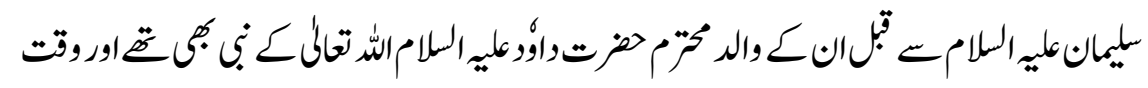

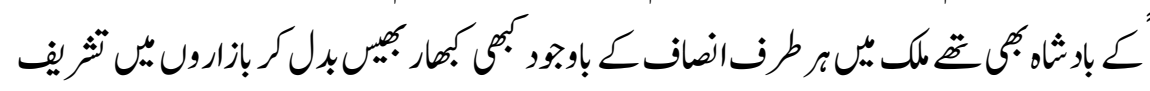

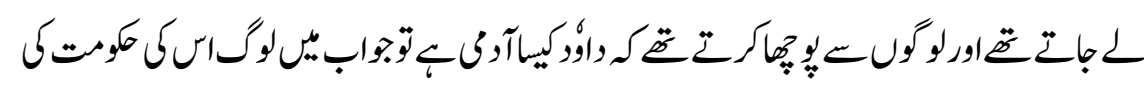

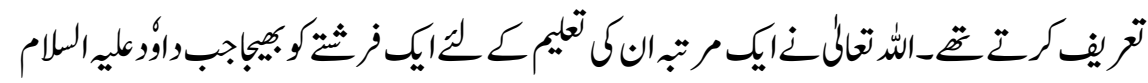

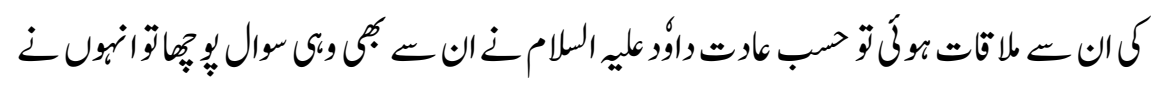

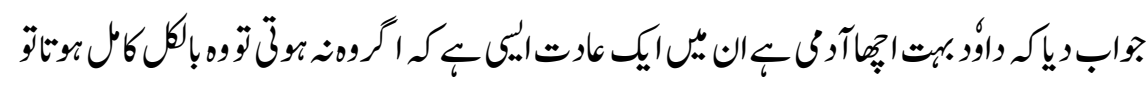

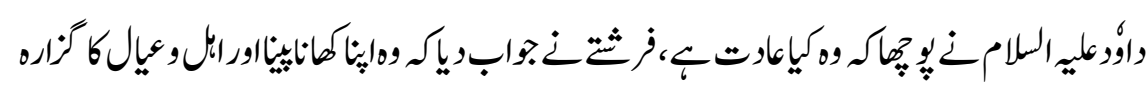

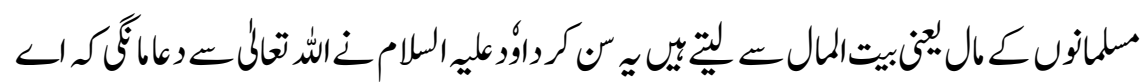

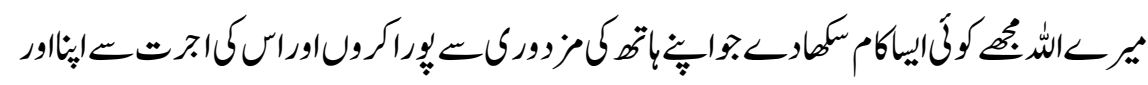

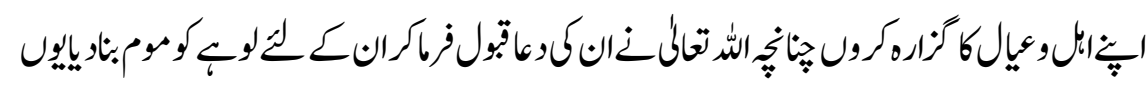

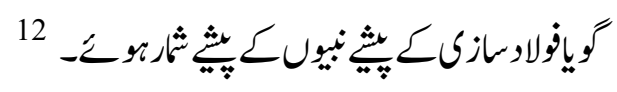

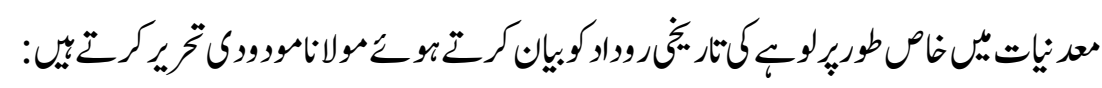

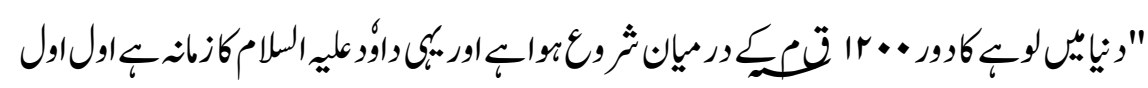

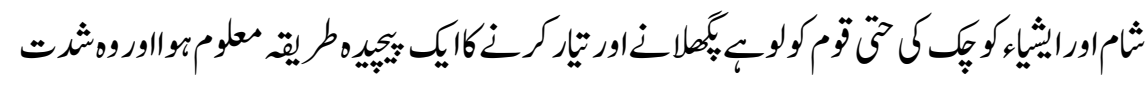

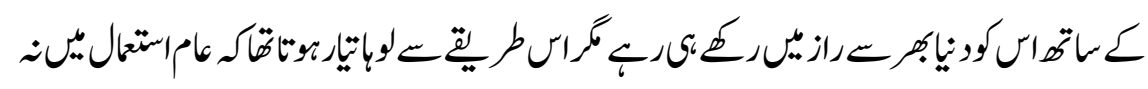

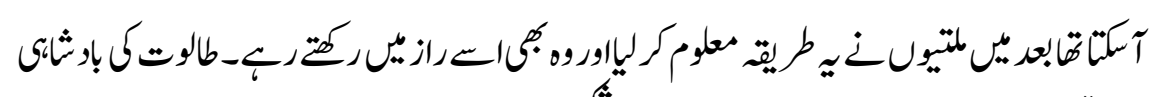

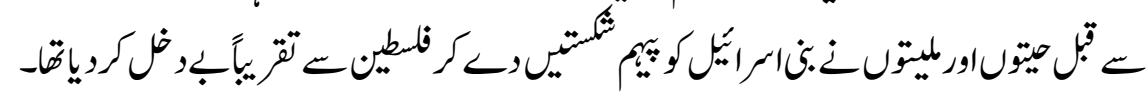

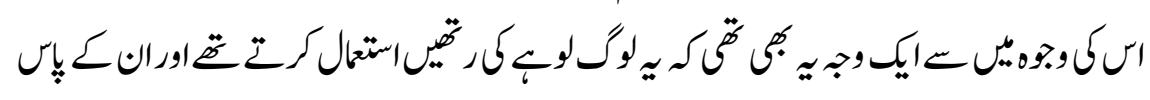

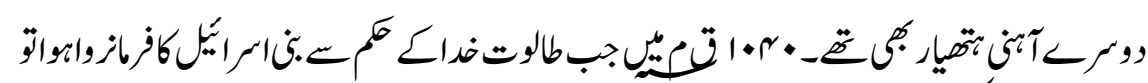

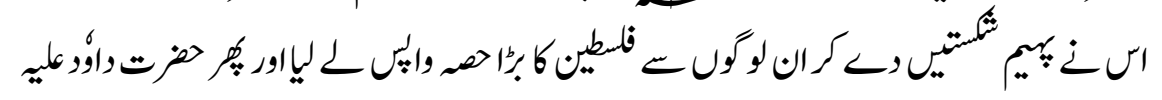




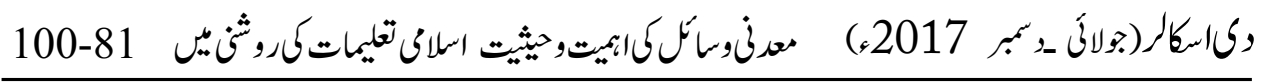

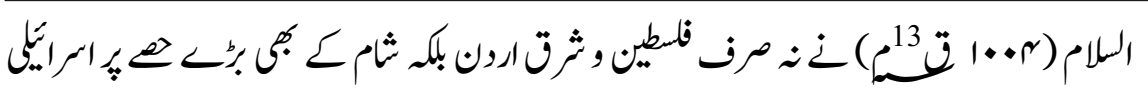

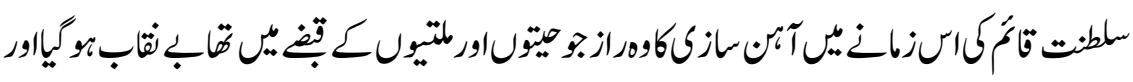

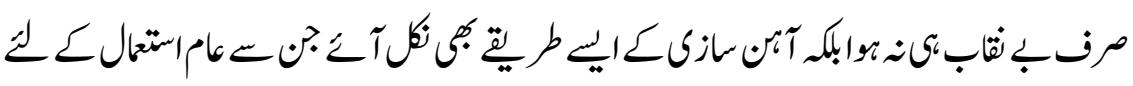

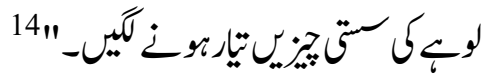

$$
\begin{aligned}
& \text { 5_اسلاميّ تصورولتاورمدنيات: }
\end{aligned}
$$

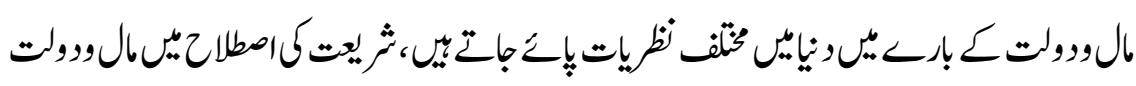

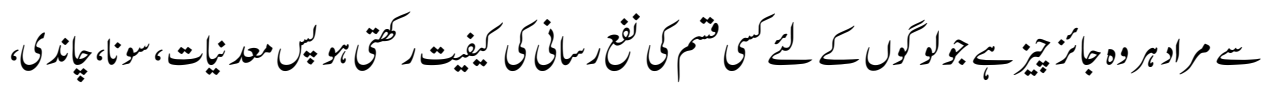

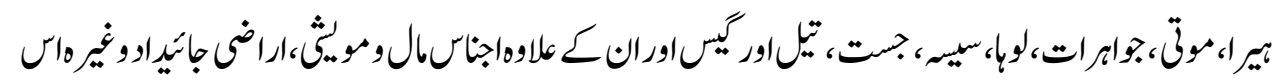

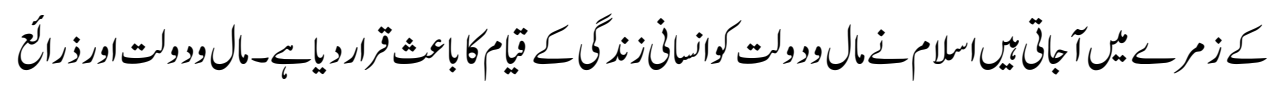

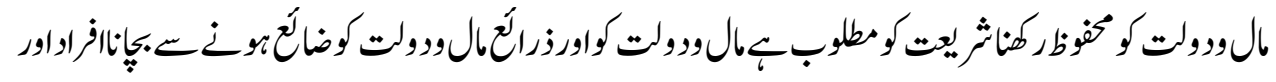

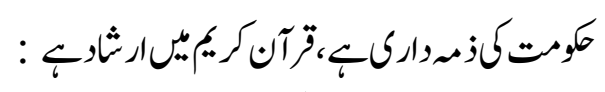

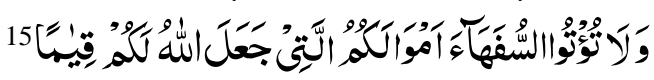

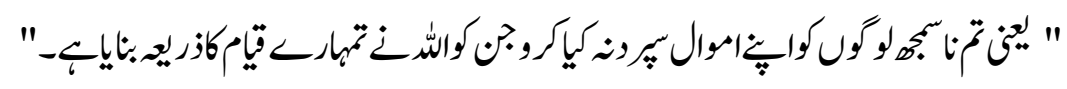

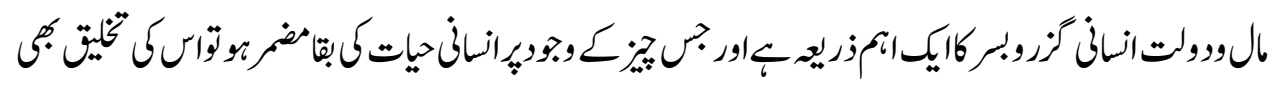

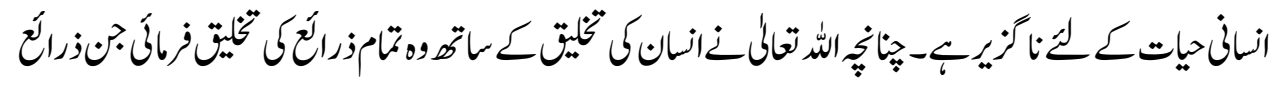

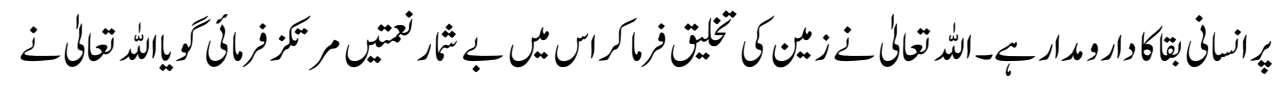

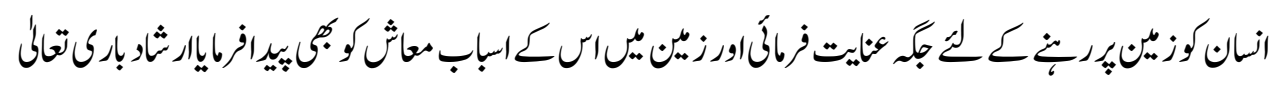

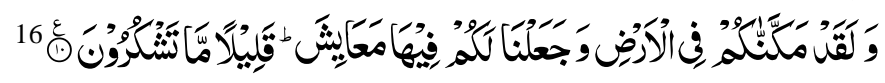

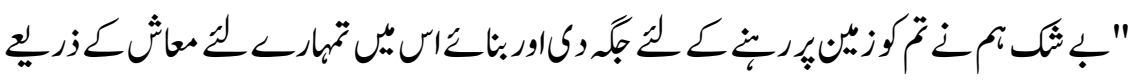

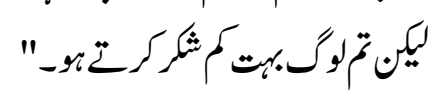

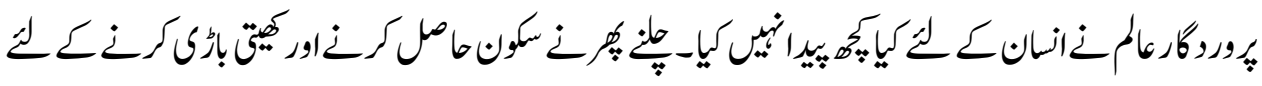

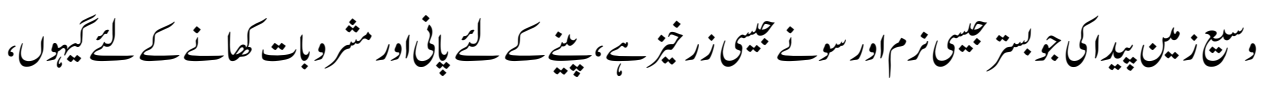




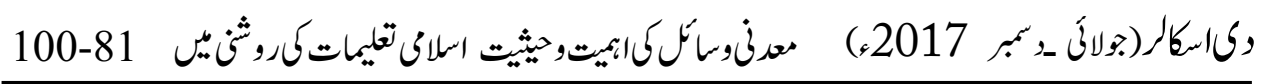

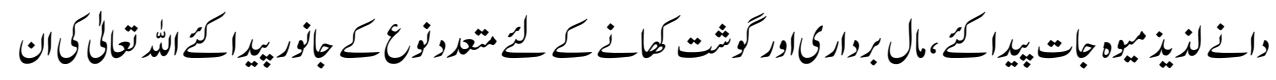

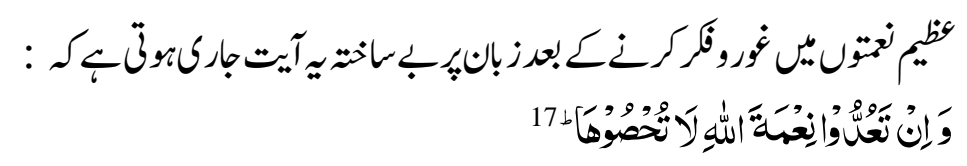

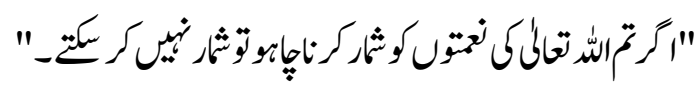

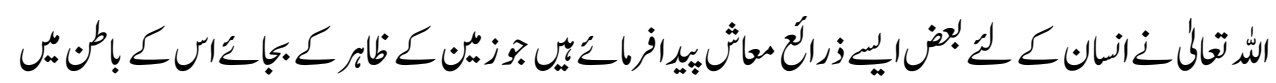

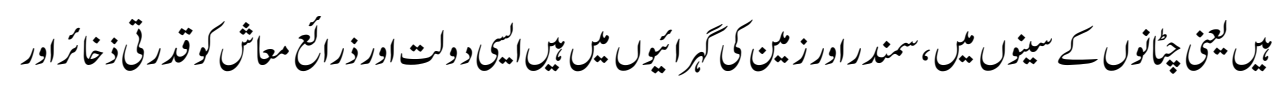

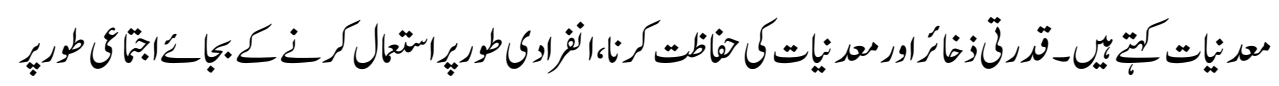

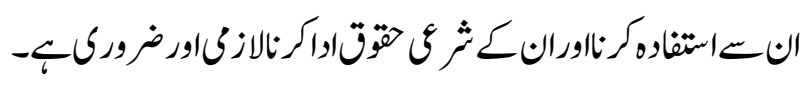

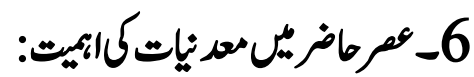

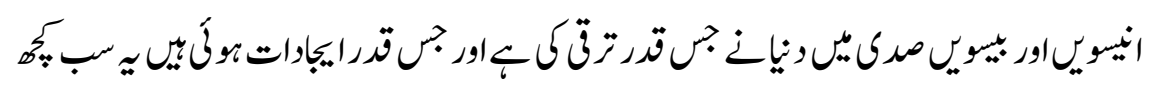

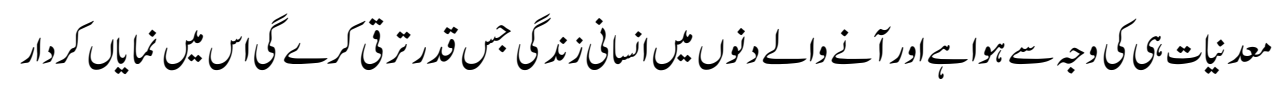

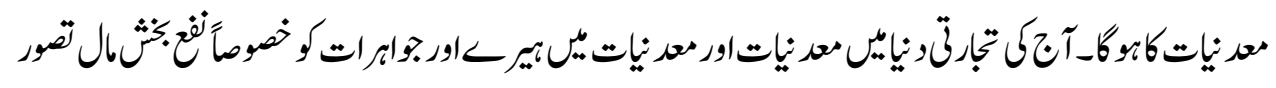

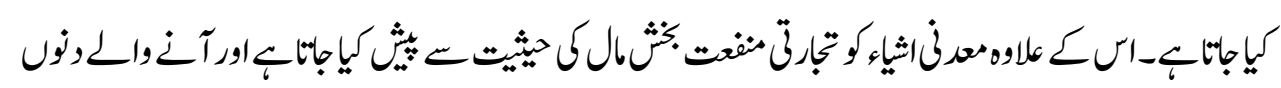

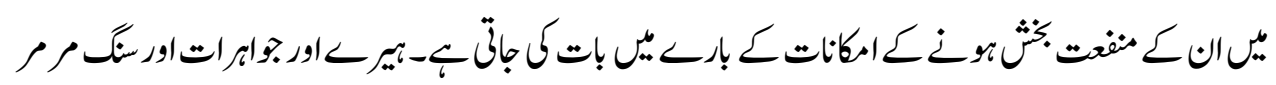

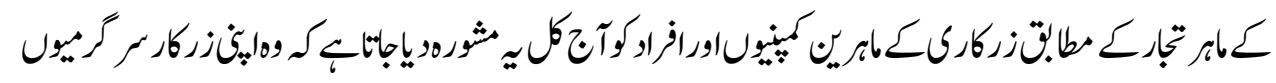

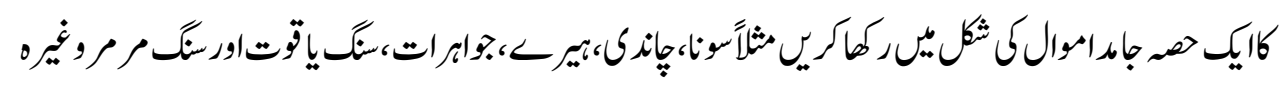

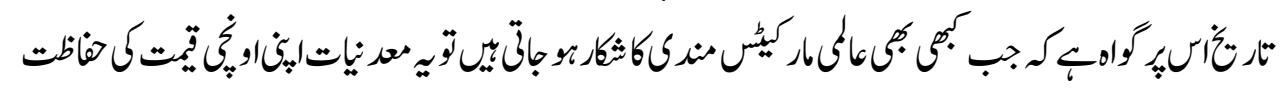

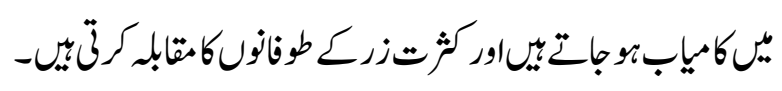

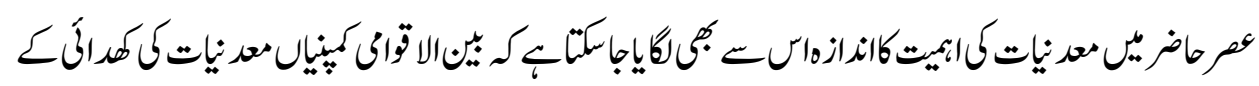

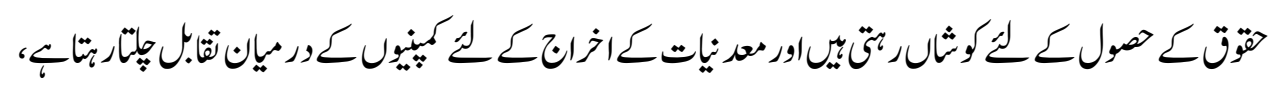

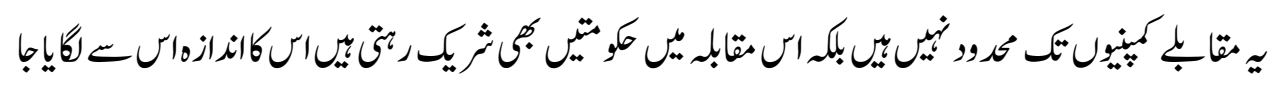

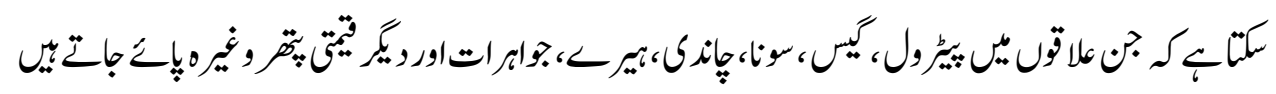

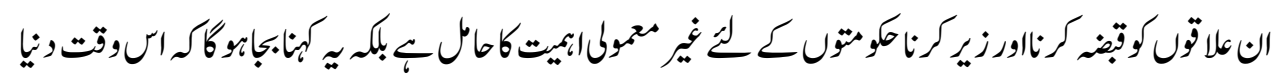




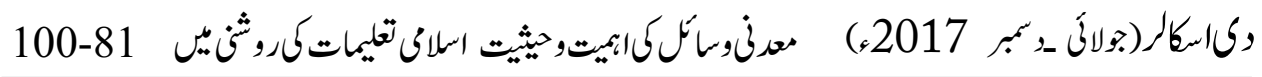

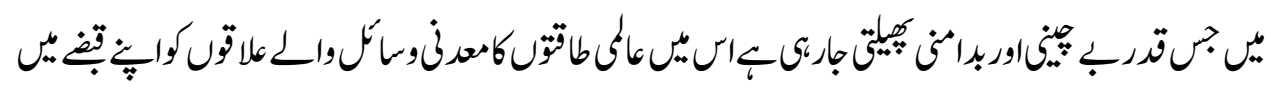

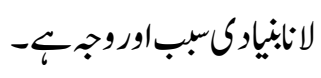

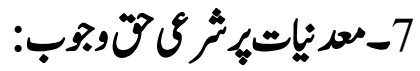

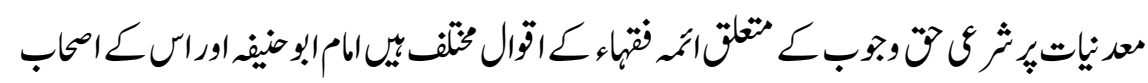

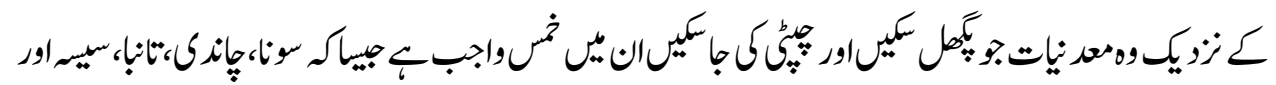

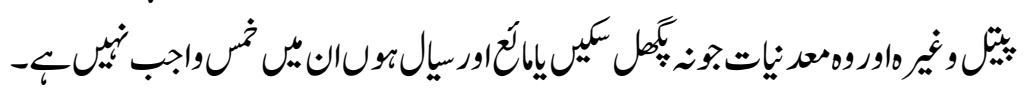

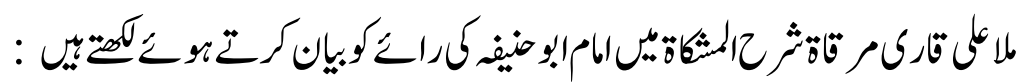

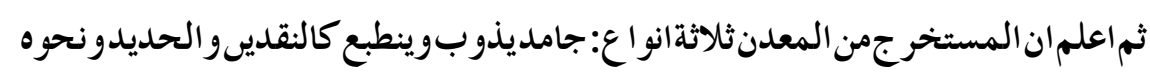

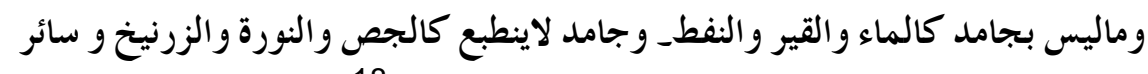

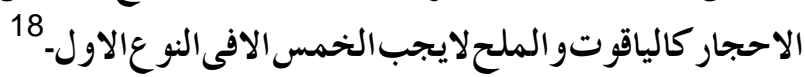

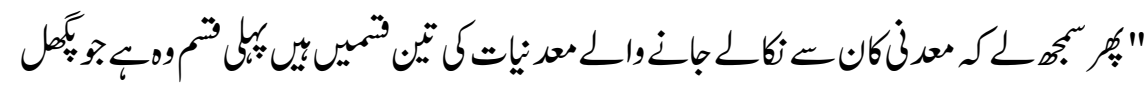

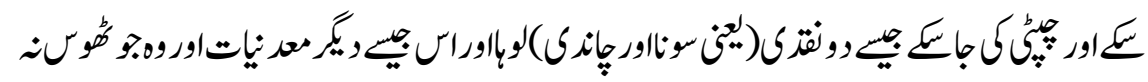

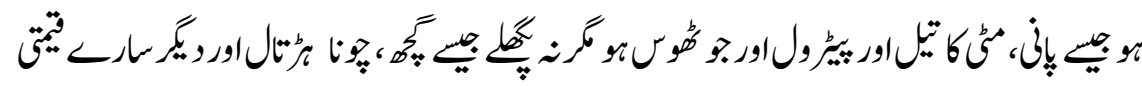

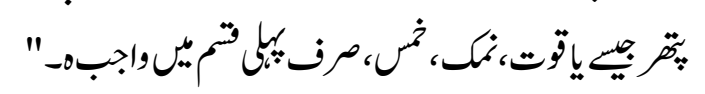

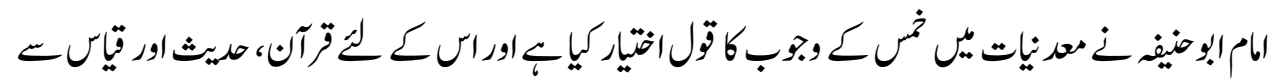

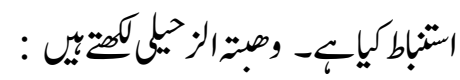

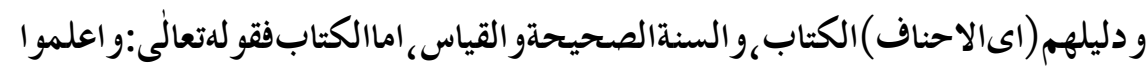

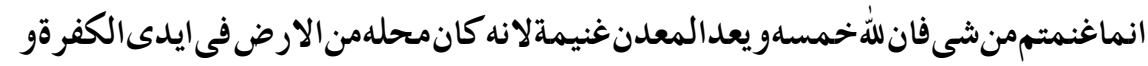

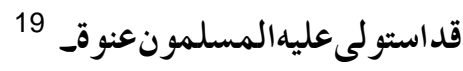

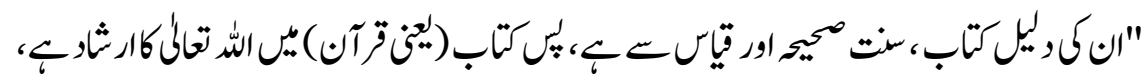

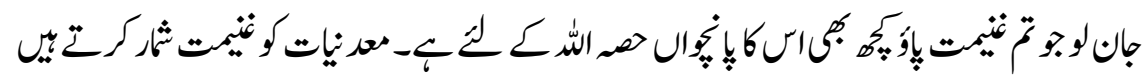

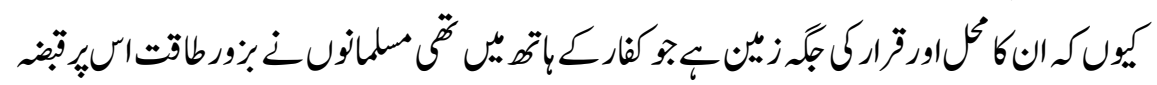
كرلي-ـ"

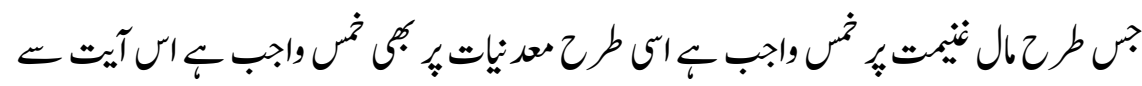




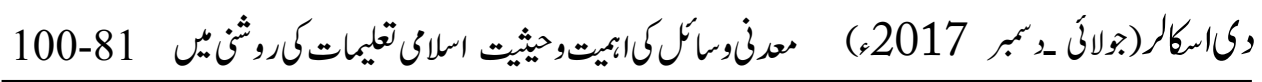

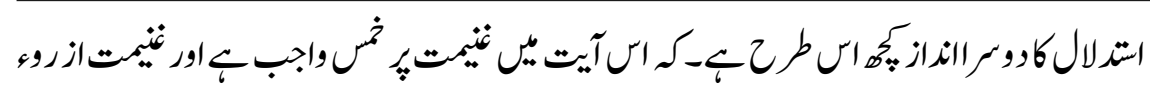

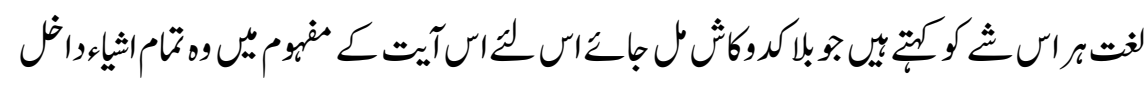

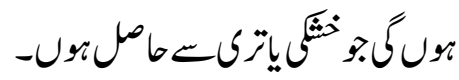

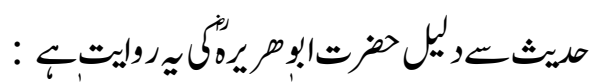

"عن ابى هريرة رضى اللّه عنه ان رسول اللهّ قال : العجما جبار ، والبير جبار و المعدن جبار و فى الر كاز 20"

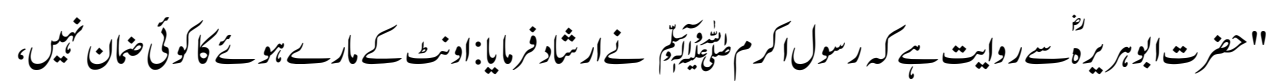

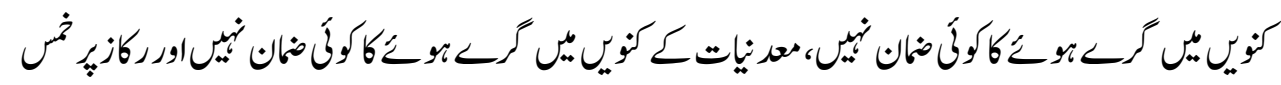

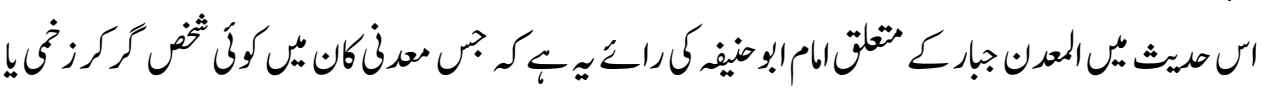

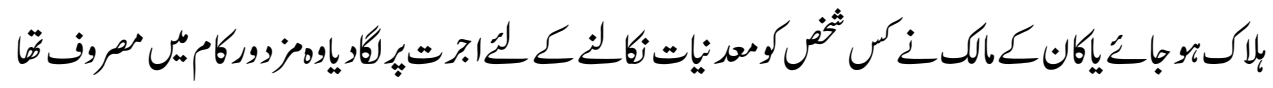

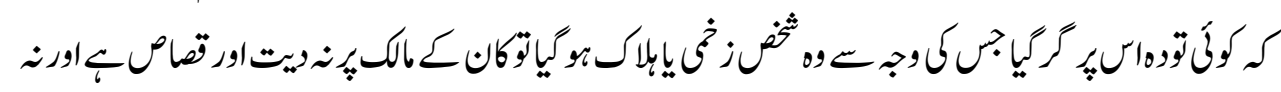

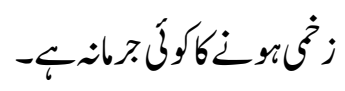

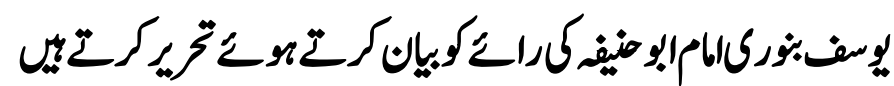

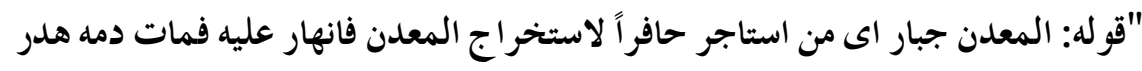

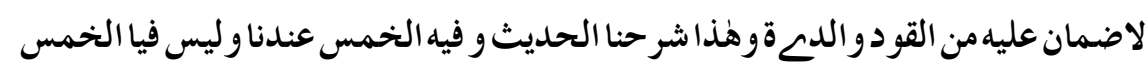

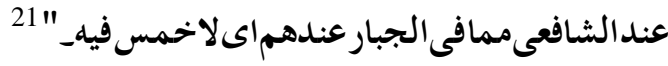

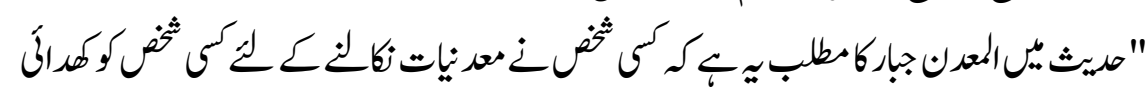

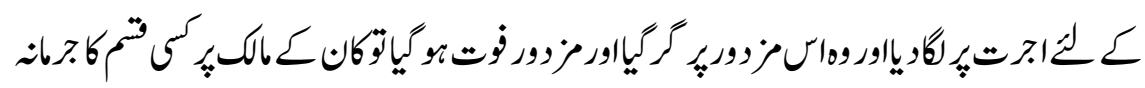

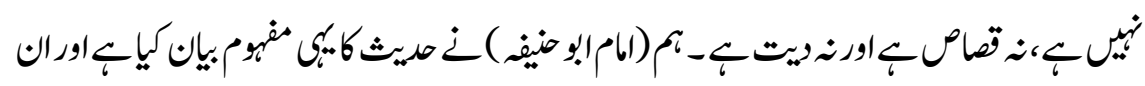

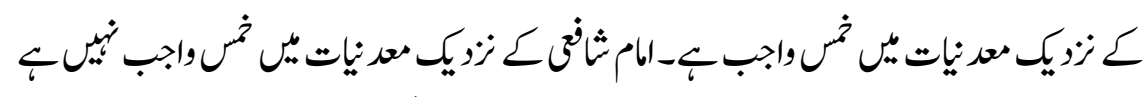

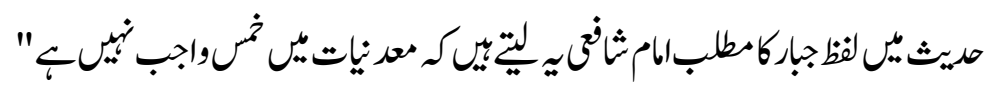

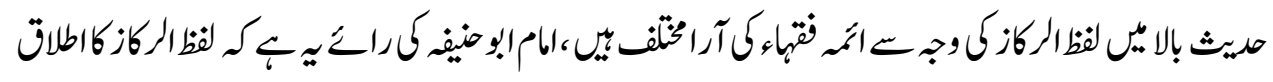

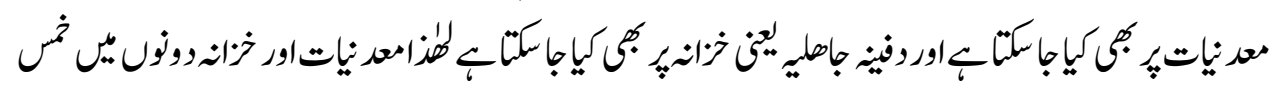
واجبـ 


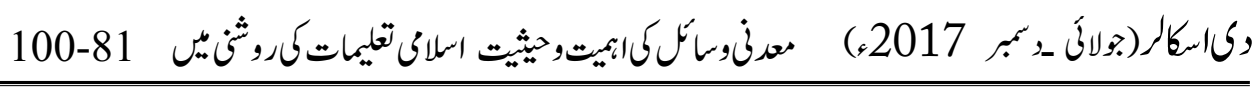

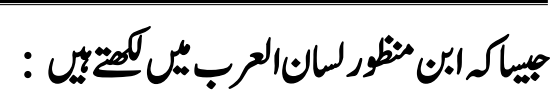

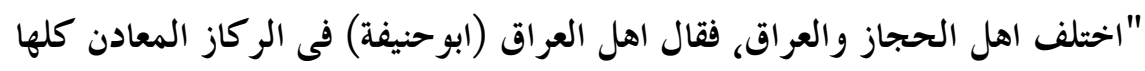

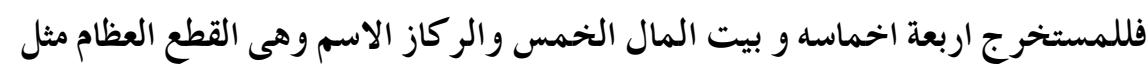

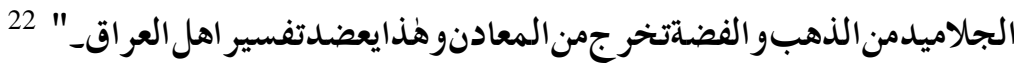

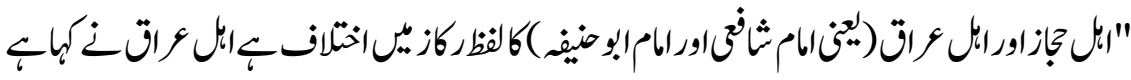

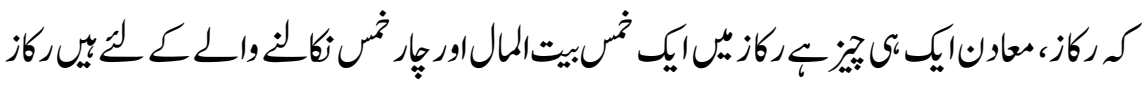

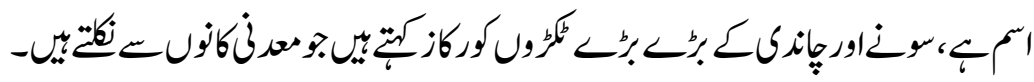

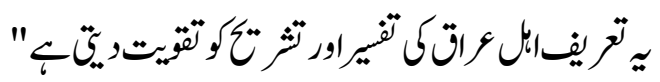

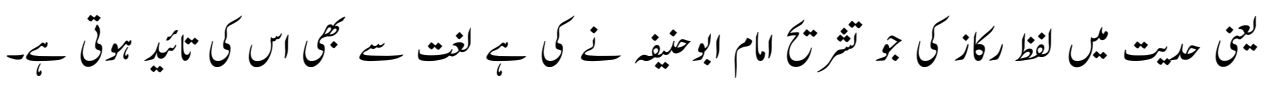

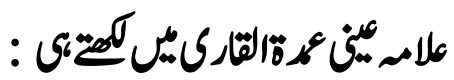

$$
\begin{aligned}
& 23 \text { "المعلدنو الر كازو احد_ } 2
\end{aligned}
$$

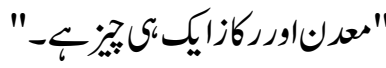

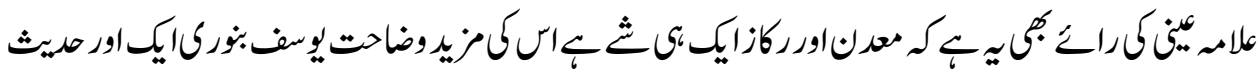

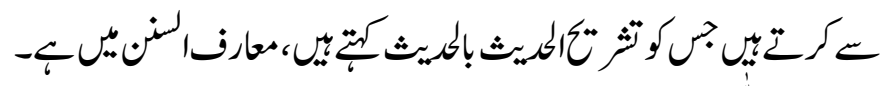

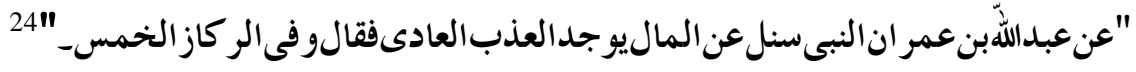

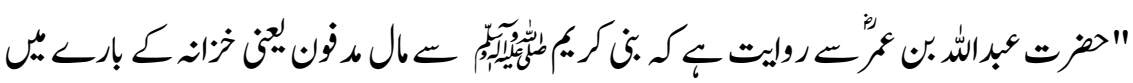

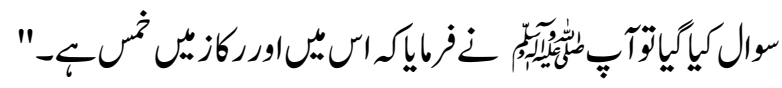

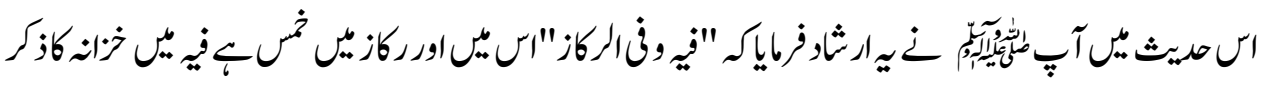

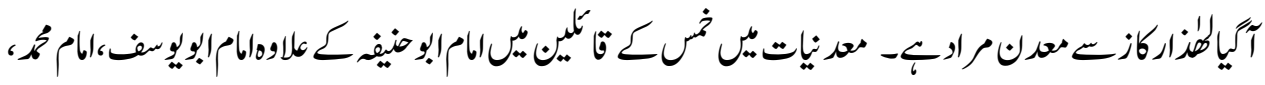

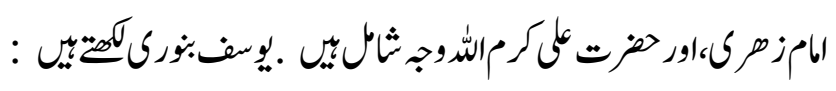

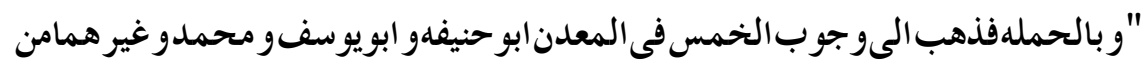

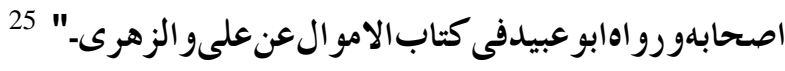

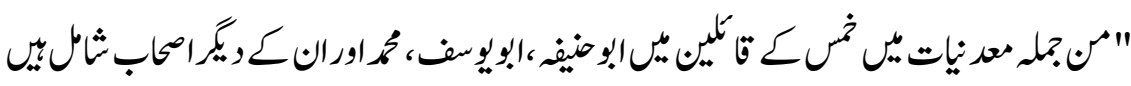

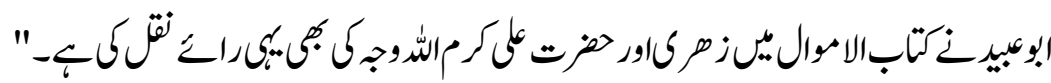

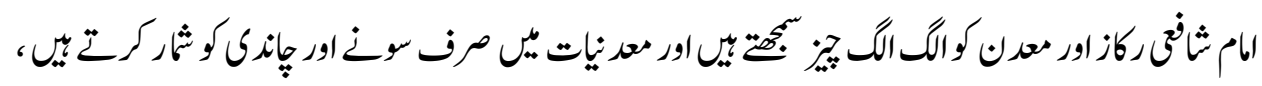




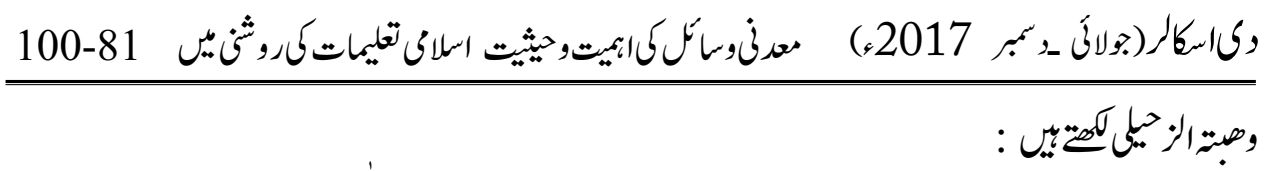
"قال الشافعى : المعدن غير الر كاز فالمعدن مايستخر جمن مكان خلق اللّّت تعالى فيهوهو خاص بالذهب والفضة." 26

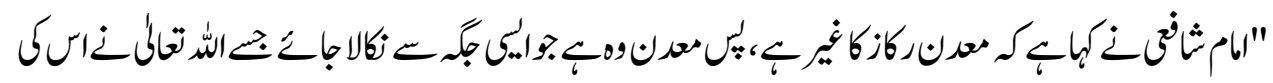

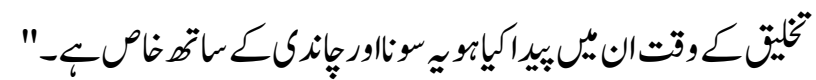

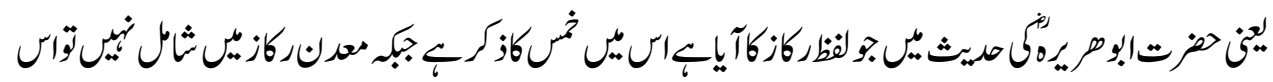

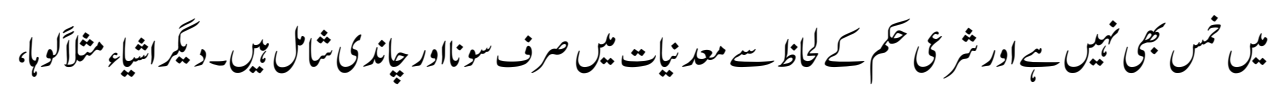

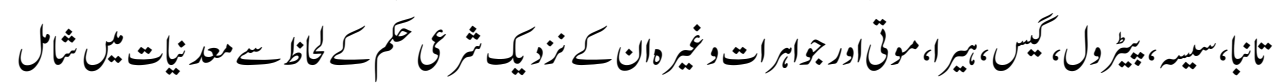

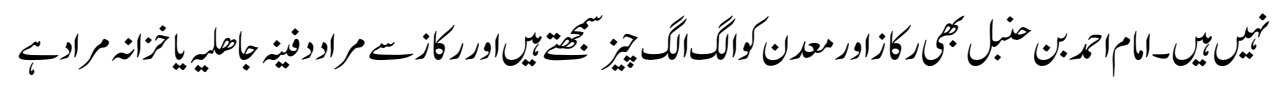

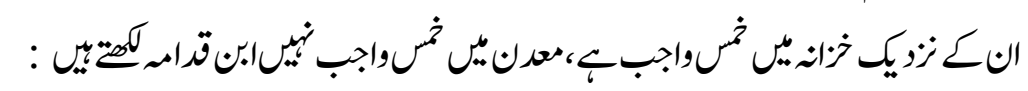

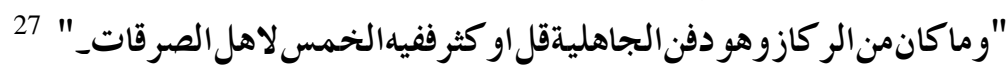

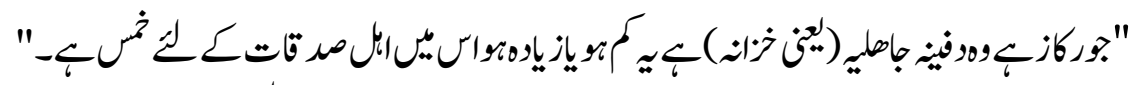

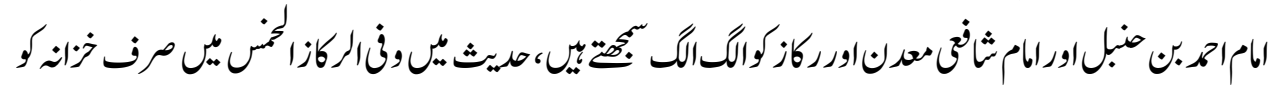

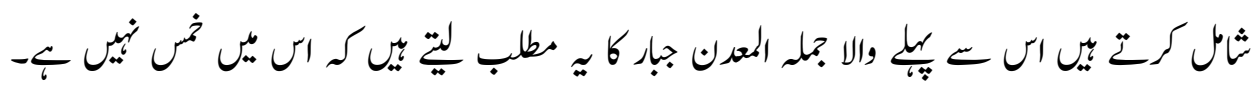

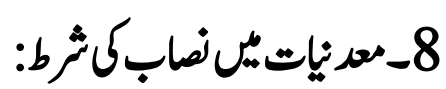

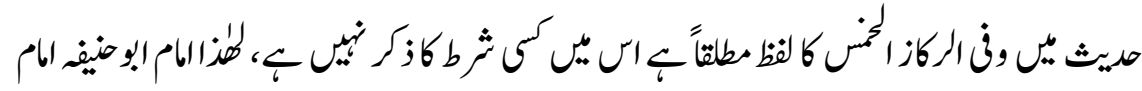

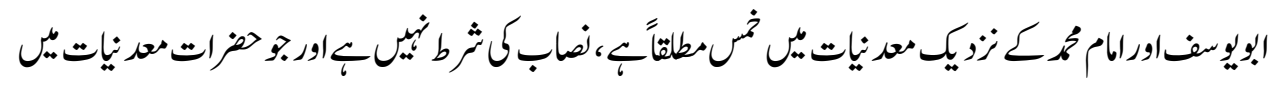

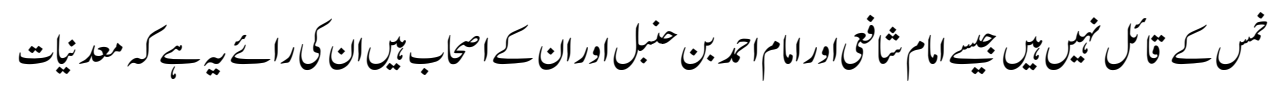

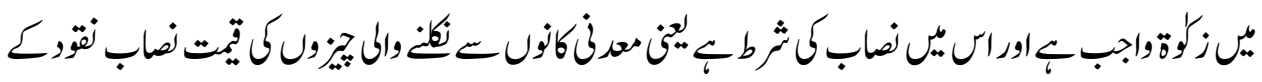

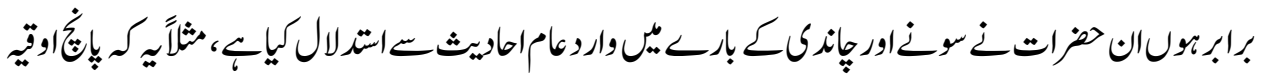

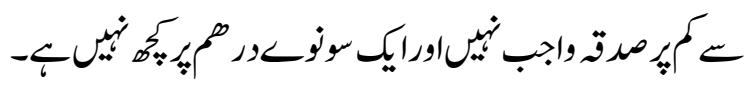

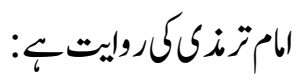

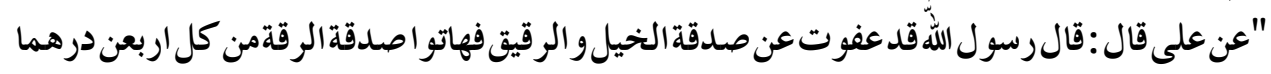

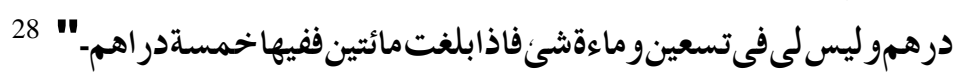




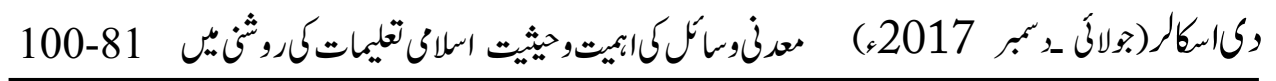

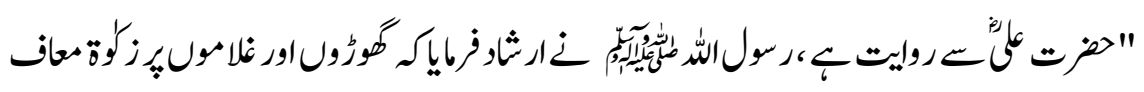

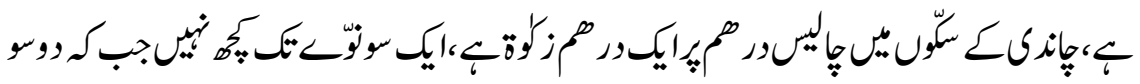

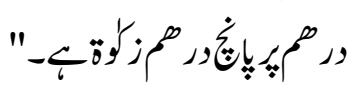

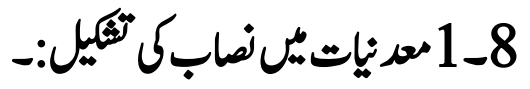

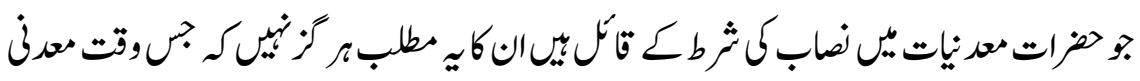

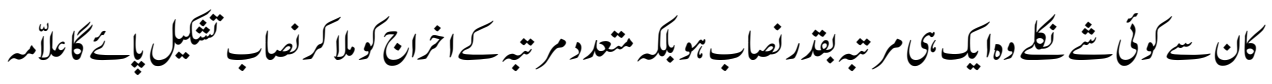

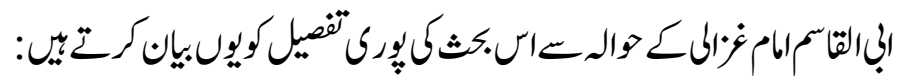

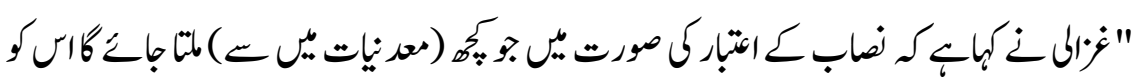

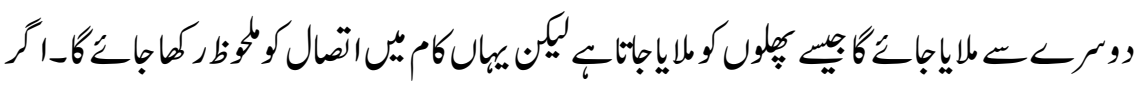

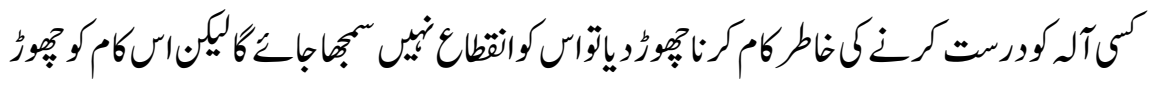

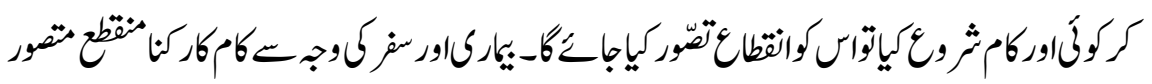

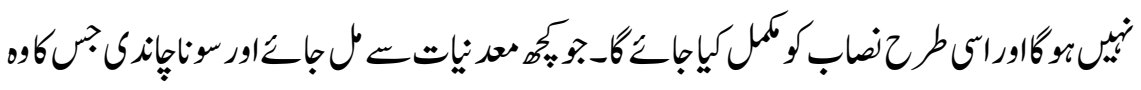

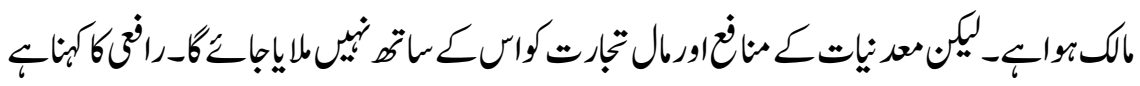

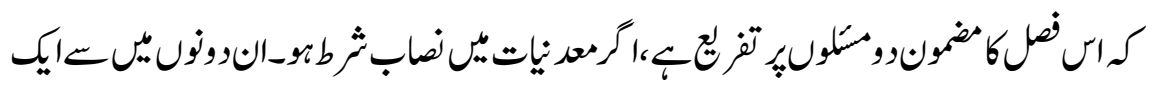

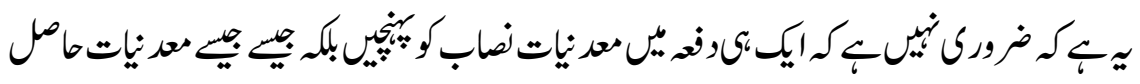

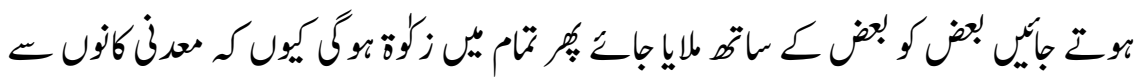

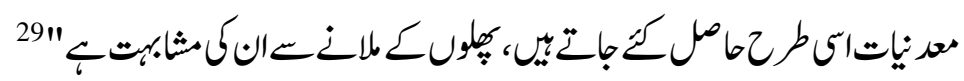

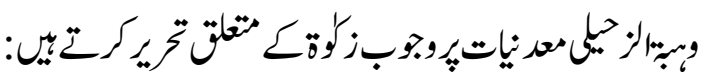

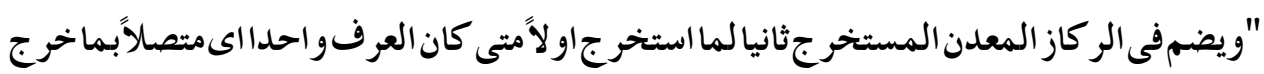

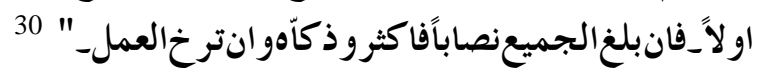

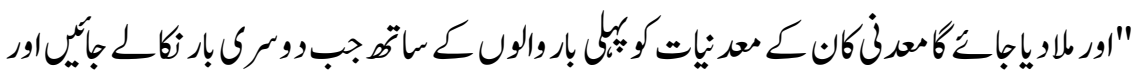

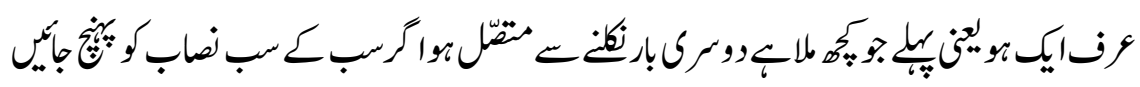

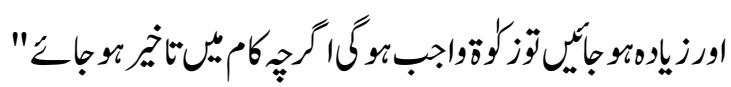

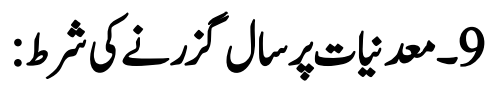

93 


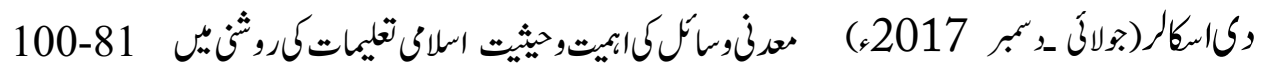

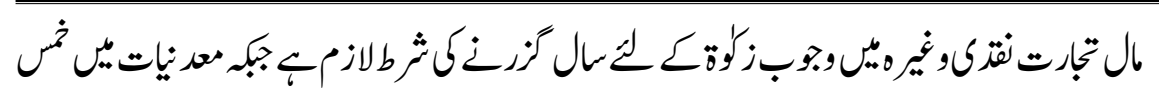

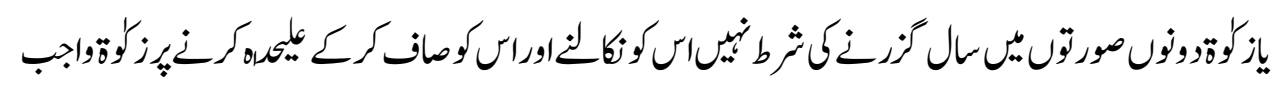

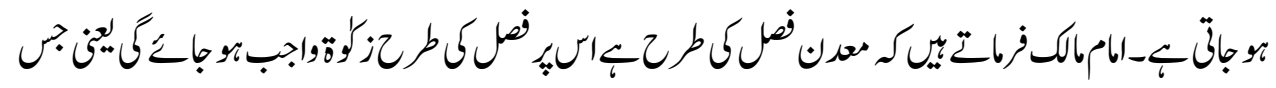

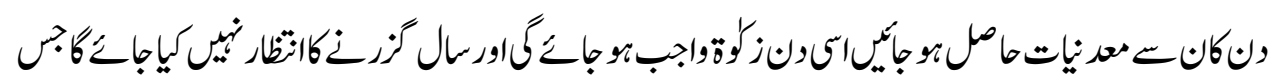

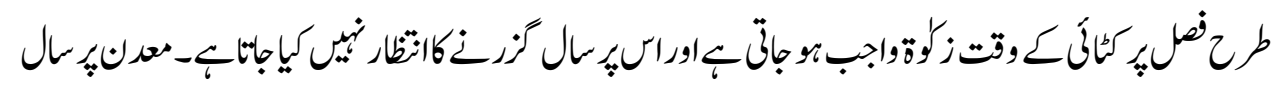

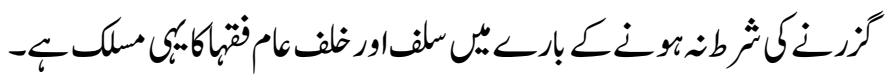

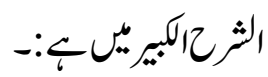

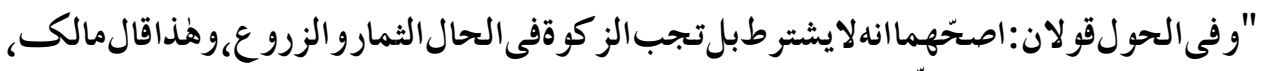

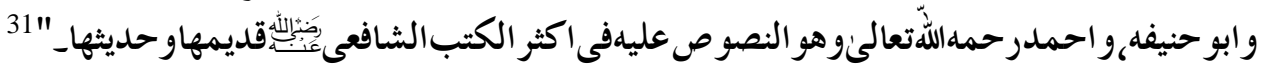

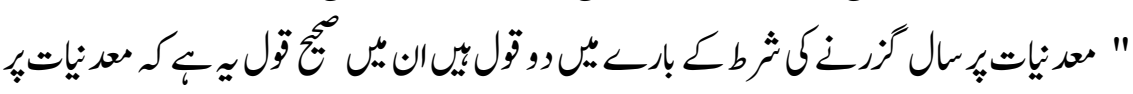

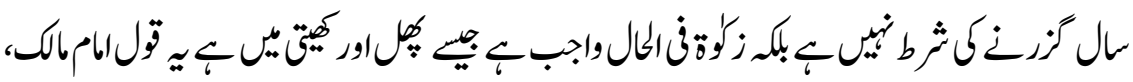

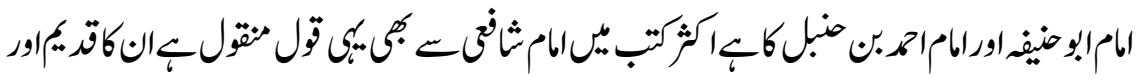

$$
\begin{aligned}
& \text { جديرتولينك-" } \\
& \text { 10- مهدنياتككتميديا تيميم: }
\end{aligned}
$$

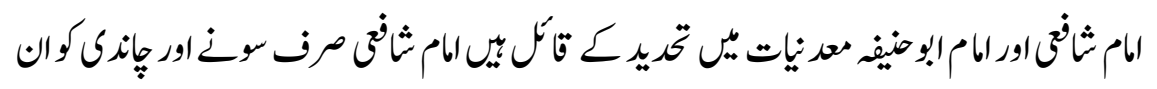

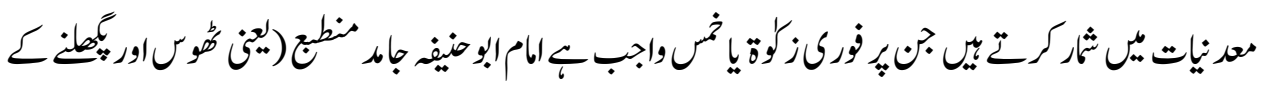

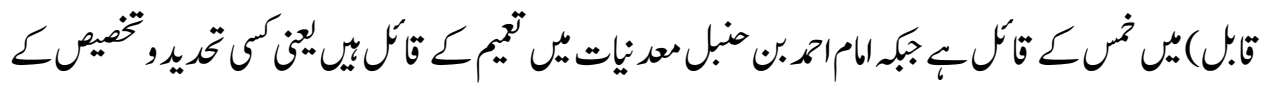

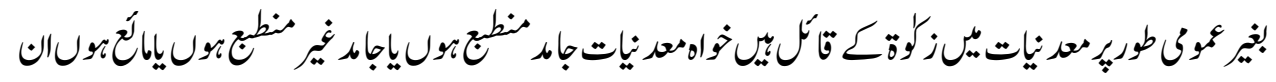

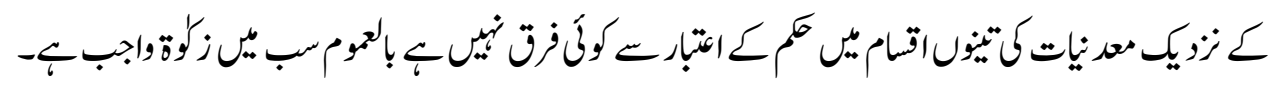

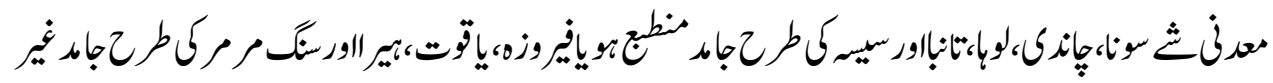

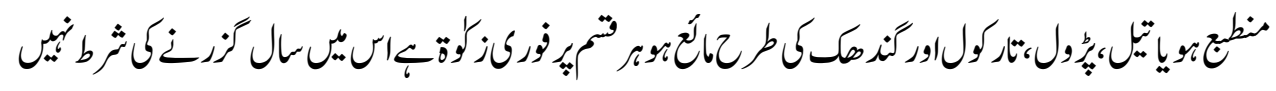

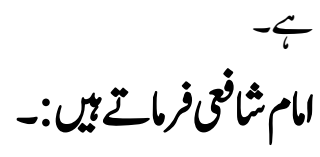
"و اذاعمل فى المعادن فلازكوة فى شى ممايخرج منها الاذهب اوورق فاما الكحل،و الرصاص، 


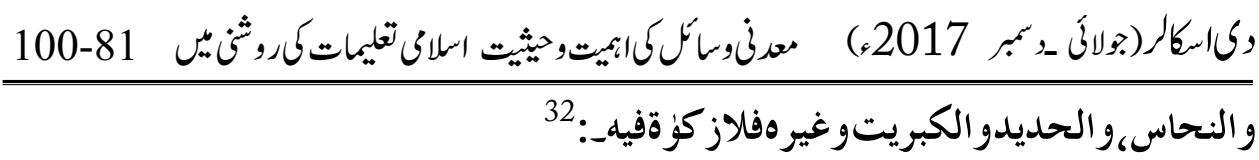

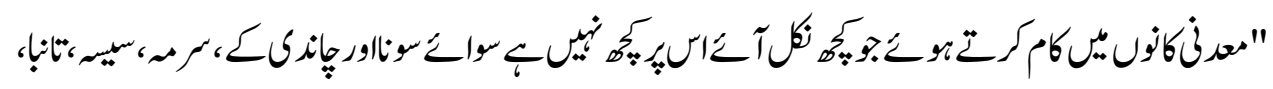

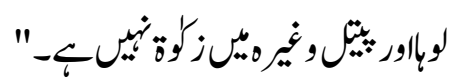

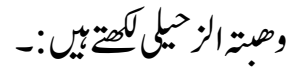

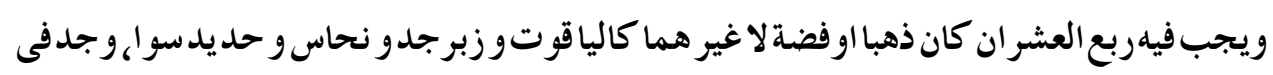
ارضمباحة|ومملو كة كحدمسلم لعمو مادلةز كوة السابقة. 33

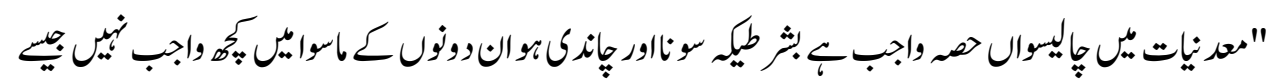

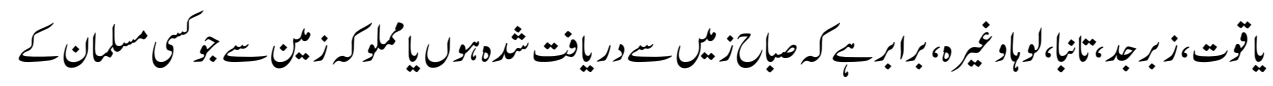

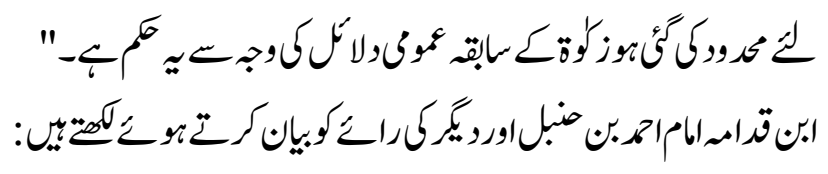

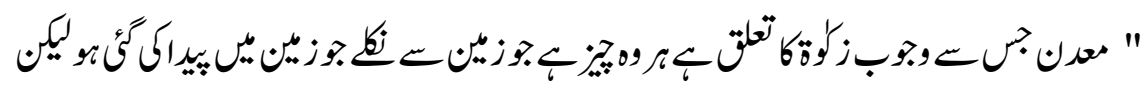

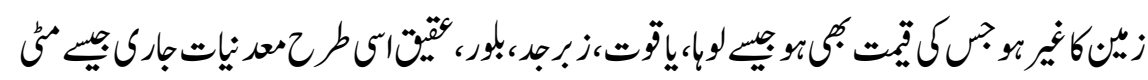

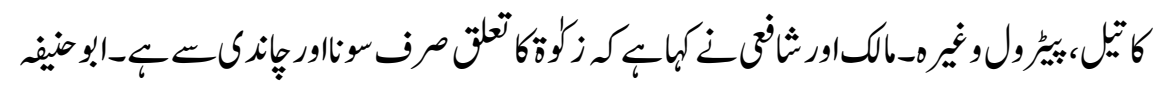

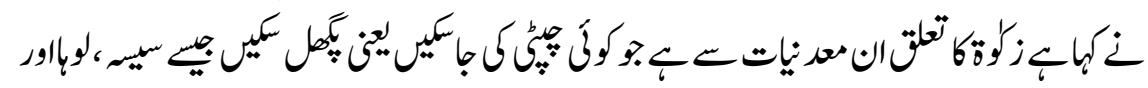

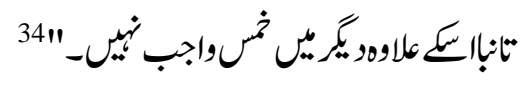

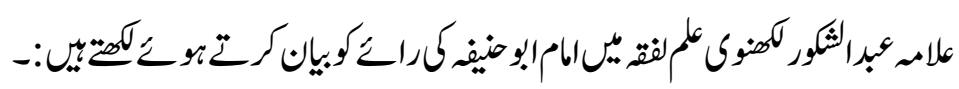

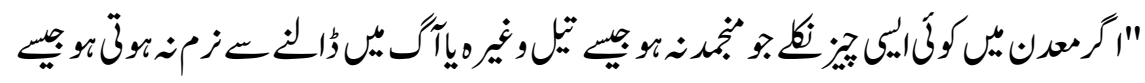

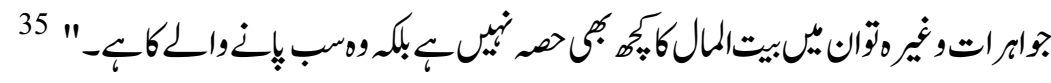

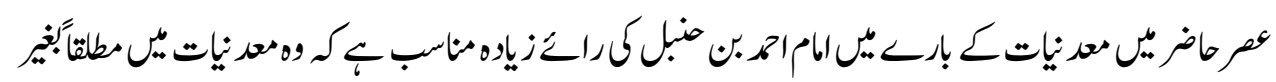

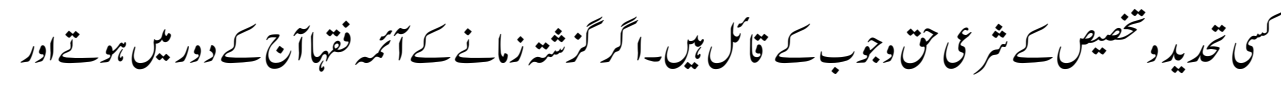

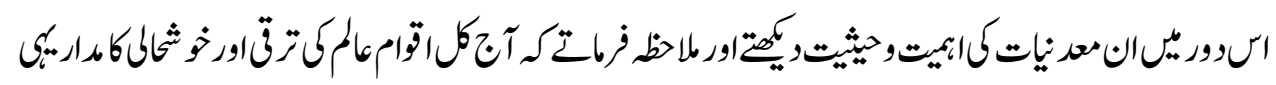

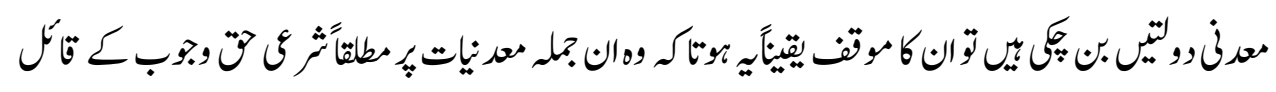
ت 11_معن نات/اورمفاوعامه: 


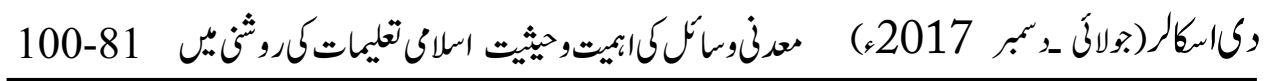

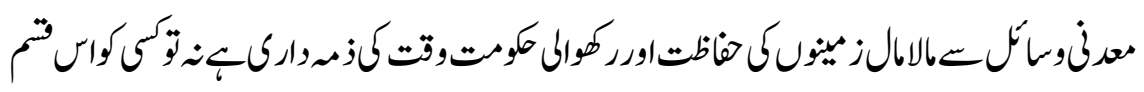

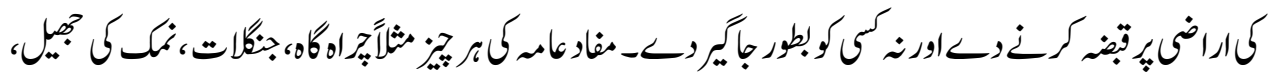

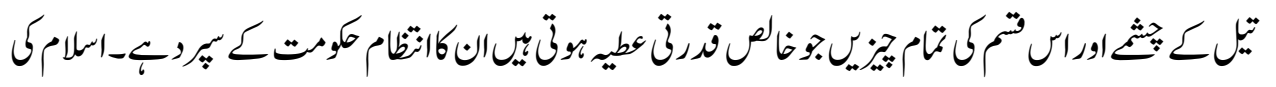

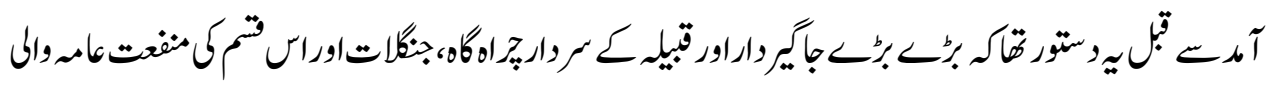

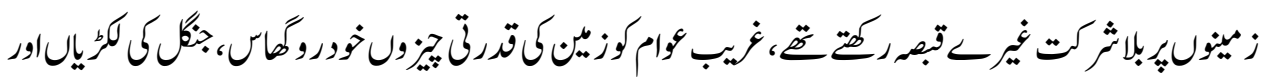

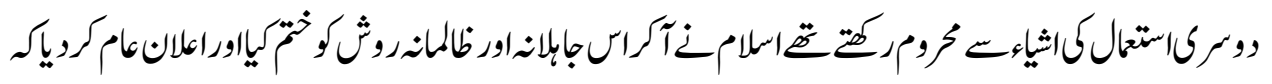

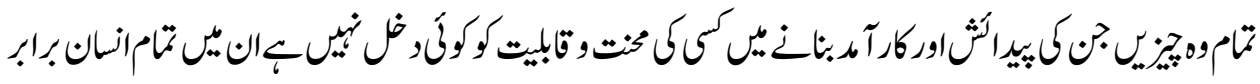

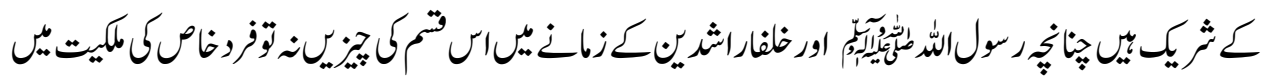

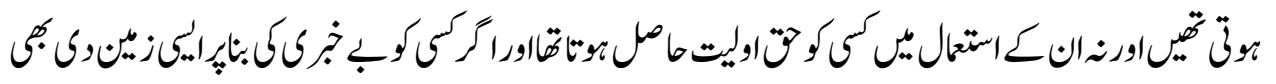

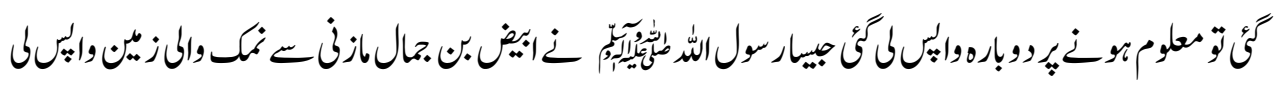

تق

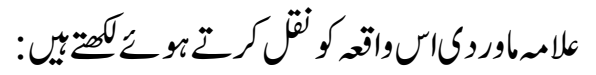

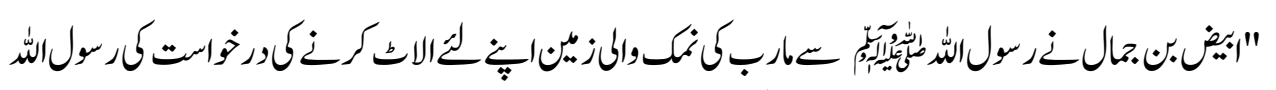

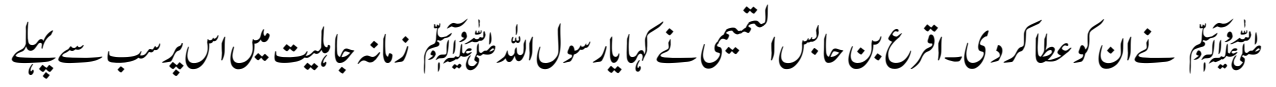

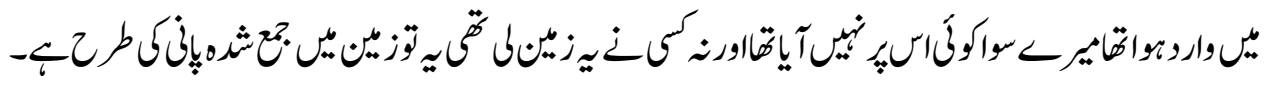

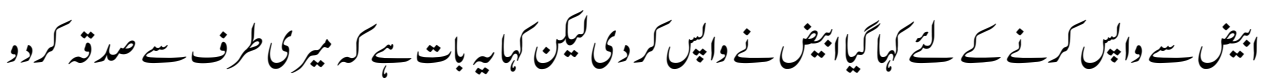

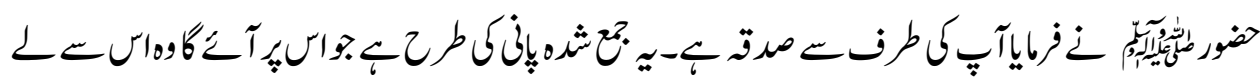

لئ-36

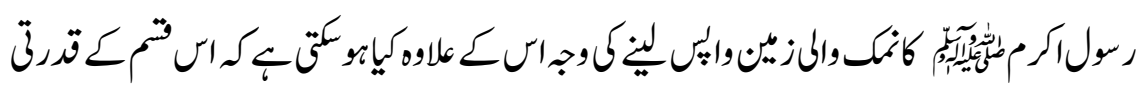

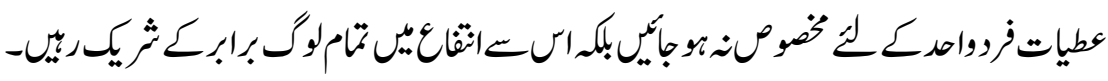

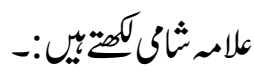

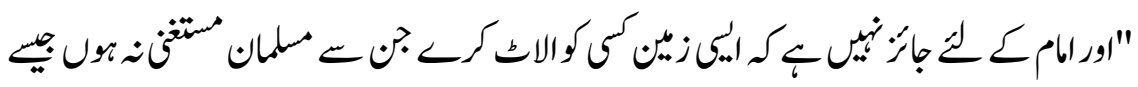

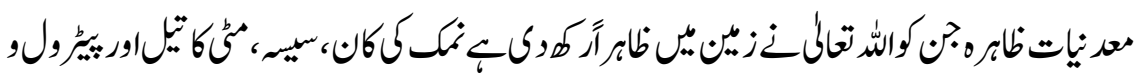

نيره"

96 


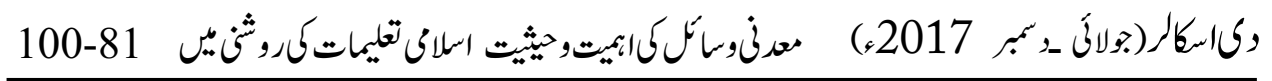

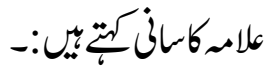

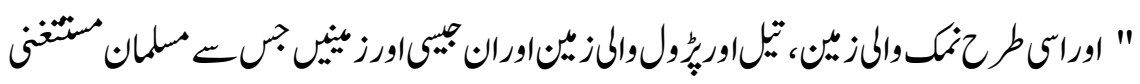

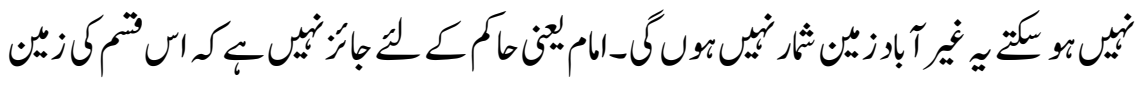

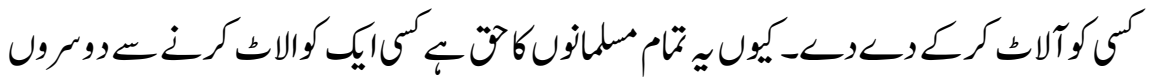

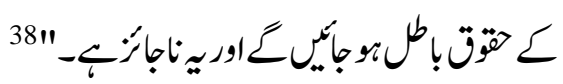

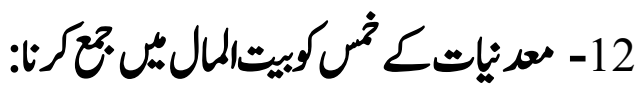

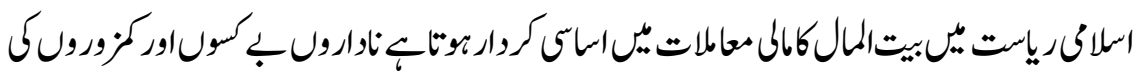

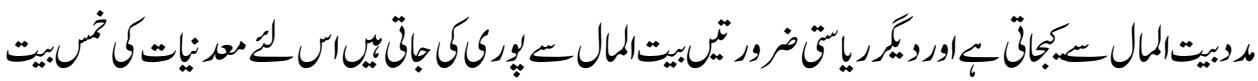

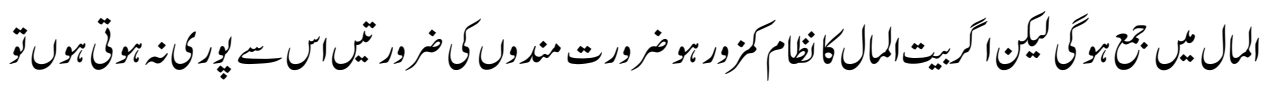

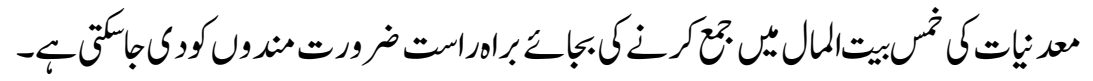

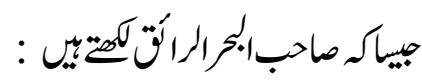

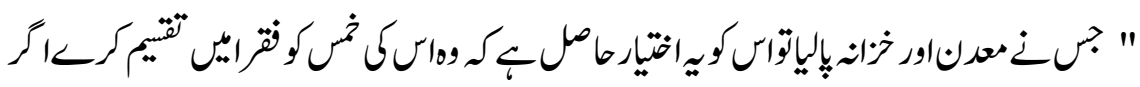

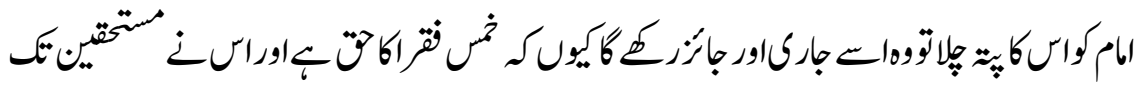

كئنيإ-ب-"

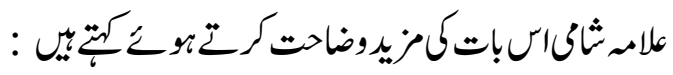

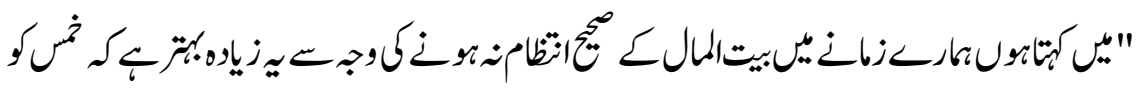

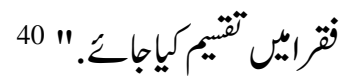

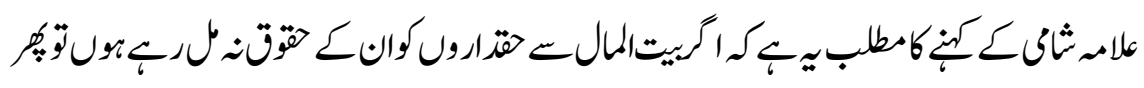

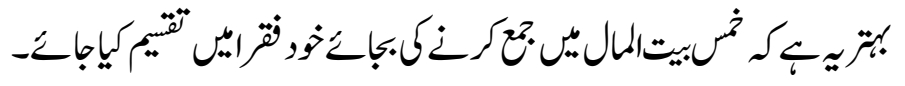

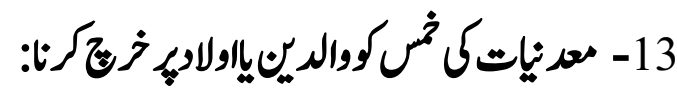

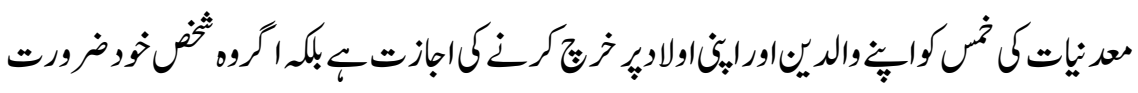

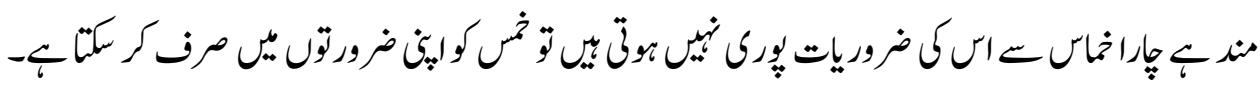

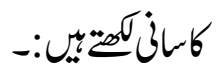

"ويجو زدفعه الى الو الدين والمولودين الفقر'، ويجوز للو اجدان يصرف الى نفسه اذا

97 


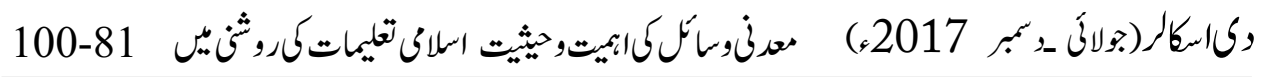

كانمحتاجاو لاتغنيها لاربعة الاخماس-" 41

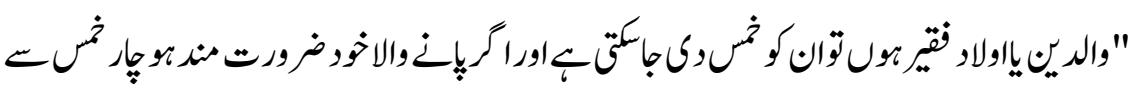

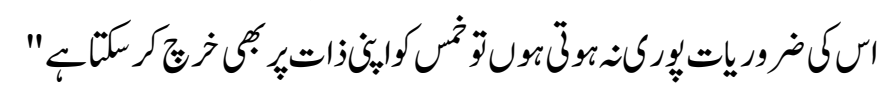

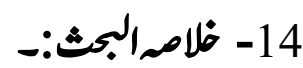

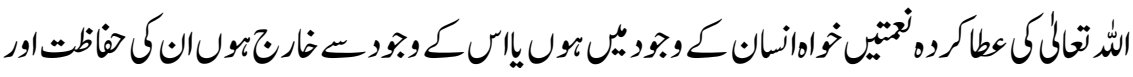

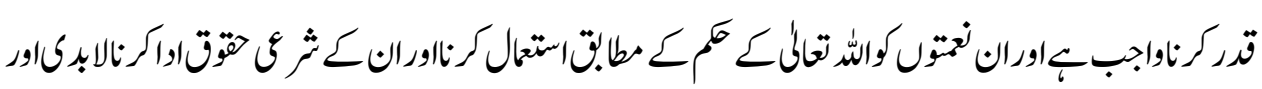

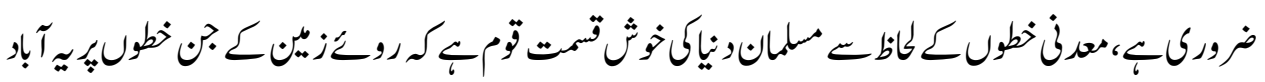

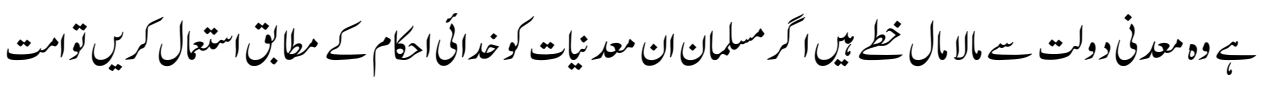

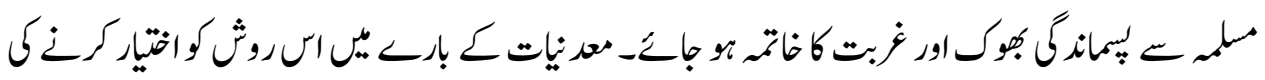

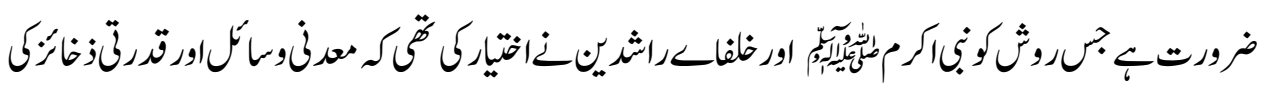

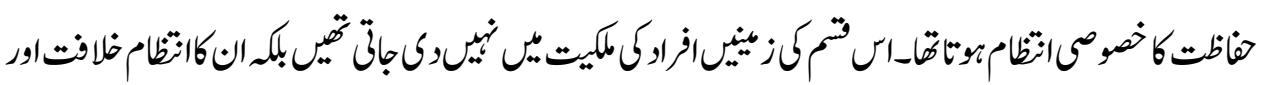

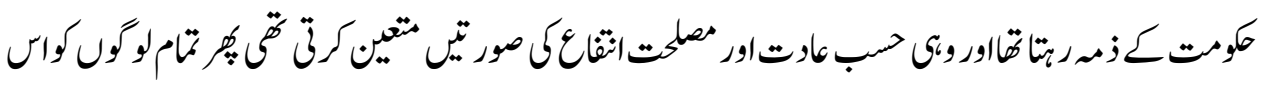
حاب

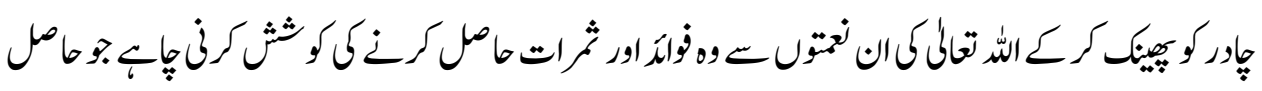
$-406$

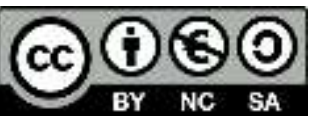

This work is licensed under a Creative Commons Attribution-NonCommercial-ShareAlike 4.0 International (CC BY-NC-SA 4.0) 


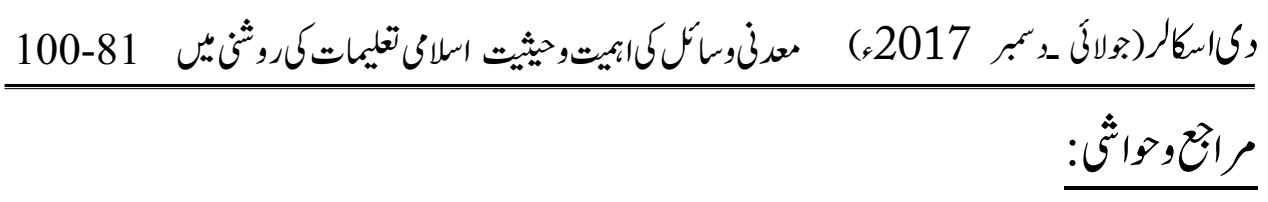

1

2

3

4

6 5

6

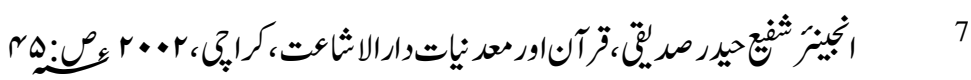

8

9

10

11

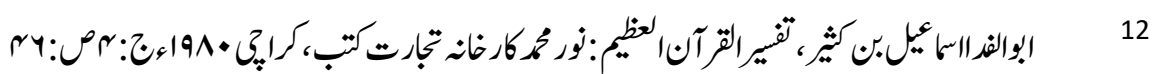
13

14

15

16 مورةالأواف: • 10

17

18

18

20

21

22

23

24 


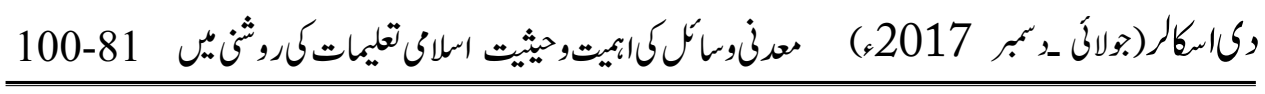

$$
\begin{aligned}
& 25 \\
& 26 \\
& 27 \\
& 28 \\
& 29 \\
& 30 \\
& 31 \\
& 332 \\
& 33 \\
& 34 \\
& 35
\end{aligned}
$$

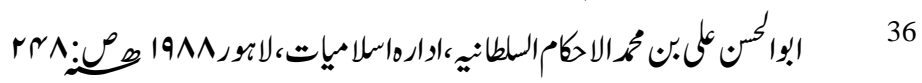

$$
\begin{aligned}
& 37 \\
& 38 \\
& 39 \\
& 40 \\
& 41
\end{aligned}
$$

